\title{
Nano-structured dynamic Schiff base cues as robust self-healing polymers for biomedical and tissue engineering applications: a review
}

\author{
Umer Shahzad Malik ${ }^{1,2} \cdot$ Muhammad Bilal Khan Niazi $^{1} \cdot$ Zaib Jahan $^{1} \cdot$ Mazhar Iqbal Zafar $^{4} \cdot$ Dai-Viet N. Vo ${ }^{2}$. \\ Farooq Sher ${ }^{3}$ (D)
}

Received: 18 August 2021 / Accepted: 2 October 2021 / Published online: 31 October 2021

(c) The Author(s) 2021

\begin{abstract}
Polymer materials are vulnerable to damages, failures, and degradations, making them economically unreliable. Self-healing polymers, on the other hand, are multifunctional materials with superior properties of autonomic recovery from physical damages. These materials are suitable for biomedical and tissue engineering in terms of cost and durability. Schiff base linkages-based polymer materials are one of the robust techniques owing to their simple self-healing mechanism. These are dynamic reversible covalent bonds, easy to fabricate at mild conditions, and can self-reintegrate after network disruption at physiological conditions making them distinguished. Here we review self-healing polymer materials based on Schiff base bonds. We discuss the Schiff base bond formation between polymeric networks, which explains the self-healing phenomenon. These bonds have induced $100 \%$ recovery in optimal cases.
\end{abstract}

Keywords Sustainable materials $\cdot$ Multifunction $\cdot$ Self-healing $\cdot$ Reversible covalent bonds $\cdot$ Coating $\cdot$ Green chemistry and tissue engineering

\begin{tabular}{|c|c|c|c|}
\hline \multicolumn{2}{|l|}{ Abbrevi } & $\mathrm{CQD}_{\mathrm{AG}}$ & $\begin{array}{l}\text { Carboxymethyl chitosan-mixed carbon } \\
\text { quantum dots }\end{array}$ \\
\hline PEG-DA & poly (ethylene glycol) & AMSCs-exo & Adipose-derived mesenchymal stem \\
\hline \multirow[t]{2}{*}{ 4sPCL-TA } & 4-Arm star-shaped polycaprolactone & & cell exosome \\
\hline & tetraaldehyde & $\mathrm{CS}-\mathrm{CNF}$ & Novel chitosan-cellulose nanofiber \\
\hline \multirow[t]{2}{*}{ AEMA } & 2-Aminoethyl methacrylate & HUVEC & Human umbilical vein endothelial cells \\
\hline & hydrochloride & AP-PDMS & Aminopropyl-polydimethylsiloxane \\
\hline \multirow{3}{*}{$\begin{array}{l}\text { DF-PEG } \\
\text { N, O-CMC } \\
\text { PPR }\end{array}$} & Functionalized polyethylene glycol & HMDI & 4,4'-Methylenebis-(cyclohexyl \\
\hline & $\mathrm{N}, \mathrm{O}$-carboxymethyl chitosan & & isocyanate) \\
\hline & Polycitrate-polymine-rhodamine B & RAFT & Addition-fragmentation chain transfer \\
\hline & polymer & PF127-CHO & Benzaldehyde-terminated Pluronic \\
\hline & & SPIONs & Superparamagnetic iron oxide \\
\hline \multirow{2}{*}{\multicolumn{2}{|c|}{$\begin{array}{l}\square \text { Farooq Sher } \\
\text { Farooq.Sher@ntu.ac.uk }\end{array}$}} & & nano- \\
\hline & & $\begin{array}{l}\mathrm{NH}_{2} \text {-PDMS-NH } \\
\text { TFME }\end{array}$ & $\begin{array}{l}\mathrm{NH}_{2} \text {-Polydimethylsiloxane- } \mathrm{NH}_{2} \\
\text { Tris(4-formylphenoxy)methylethane }\end{array}$ \\
\hline \multicolumn{2}{|c|}{1 Department of Chemical Engineering, Schoo } & DGEBA & Bisphenol A diglycidyl ether \\
\hline
\end{tabular}

\section{Introduction}

2 Institute of Environmental Sciences, Nguyen Tat Thanh University, Ho Chi Minh City 755414, Vietnam

3 Department of Engineering, School of Science and Technology, Nottingham Trent University, Nottingham NG11 8NS, UK

4 Department of Environmental Sciences, Quaid-i-Azam University, Islamabad 45320, Pakistan

The past three decades have seen expeditious advances in applications of polymer materials (Wang et al. 2019c) such as their extensive use in electronic devices (Sadasivuni et al. 2020), photonic technologies (Kumi Barimah 
et al. 2020), packings (Batista et al. 2019), insulations (Zhou et al. 2017), structural applications (Chaudhary and Ahmad 2020), paints (Weimer et al. 2020), glues (Wang et al. 2020c), lubricants (AlMaadeed et al. 2020), elastomers (Cummings et al. 2020), rubbers (Lai et al. 2020), coatings (Acosta et al. 2020), medical applications (Romero et al. 2020), personal health care, hygiene and in separation technologies (Yong and Zhang 2020). Both synthetic and natural polymers are so essential and ubiquitous that now it is unimaginable to think life without them. The heavy reliance upon polymers is because of their unique properties and the fact that these can be tailored and tuned according to the requirements. On the other hand, polymer materials are vulnerable to damages, failures, and degradations during their prolonged service (Kian et al. 2019; Nor et al. 2019).

These failures in polymers develop due to long-term stress, fatigue, structural flaws, or stress-cracking agents. Engineering research has focussed traditionally on either the innovative design of materials or on increasing the robustness of materials to damage, yet materials are eventually failed (Sultan et al. 2009). When a load is subjected to material, it tends to damage at the macro or micro scale. Macro damages would break the material apart, while micro damages would affect the characteristics of the material (JE et al. 2020). Damages at the microscale can repair through self-healing technology. Self-healing materials are capable of restoring the integrity of their structure after failure/crack, e.g. in living species. These materials have a built-in ability to autonomically repair damages without human intervention (Reddy et al. 2020). Thus, self-healing has been demonstrated in different systems like in supramolecular network (Zhang et al. 2020a), dendrimer-clay, metal-ion polymer systems, multicomponent-systems, and linear polymer systems (Surendran and Thomas 2020). The self-healing concept in polymers was coined in the 1980s (Jud et al. 1981) and has roots in the biological concept of self-healing like wound and bone healing in humans. In nature, the specific components are supplied to the location where healing is required. Following are the steps of self-healing in living species, inflammation, cell proliferation and remodelling of matrix (Fig. 1).

Similarly, in synthetic materials, self-healing agents are dispatched from the carrier either via capsule or vascular to the repairing site for recovery of the cracks ( $\mathrm{Li}$ et al. 2020b). Triggering is the initial action in the repairing process that senses and indicates the urgency to alleviate, immediately respond to the crack/damage, and dispatch the healing agents to the affected site (transport). Repairing the crack/damage is the last step in healing rapture. The comparison of biological self-healing with synthetic self-healing is presented in Fig. 1. Looking at different chemistries of self-healing materials, in-depth scientific literature has divided self-healing methodologies into extrinsic self-healing and intrinsic selfhealing materials (Vijayan and AlMaadeed 2016; Jiang et al. 2019; Yuan et al. 2019).

\section{Self-healing methodologies}

\section{Extrinsic self-healing}

Extrinsic self-healing, the first generation of self-repairing materials, involves external healing agents in the healing phenomenon (Dai et al. 2019). These types of materials do not have the autonomous self-healing capabilities and hence need encapsulation of external healing agents (Xiong et al. 2018), two frequently approaches in use are microvascular network and microencapsulation. In both, the triggering is initiated by the rapture/damage/crack of polymer material. Extrinsic self-healing processes are simple where healing

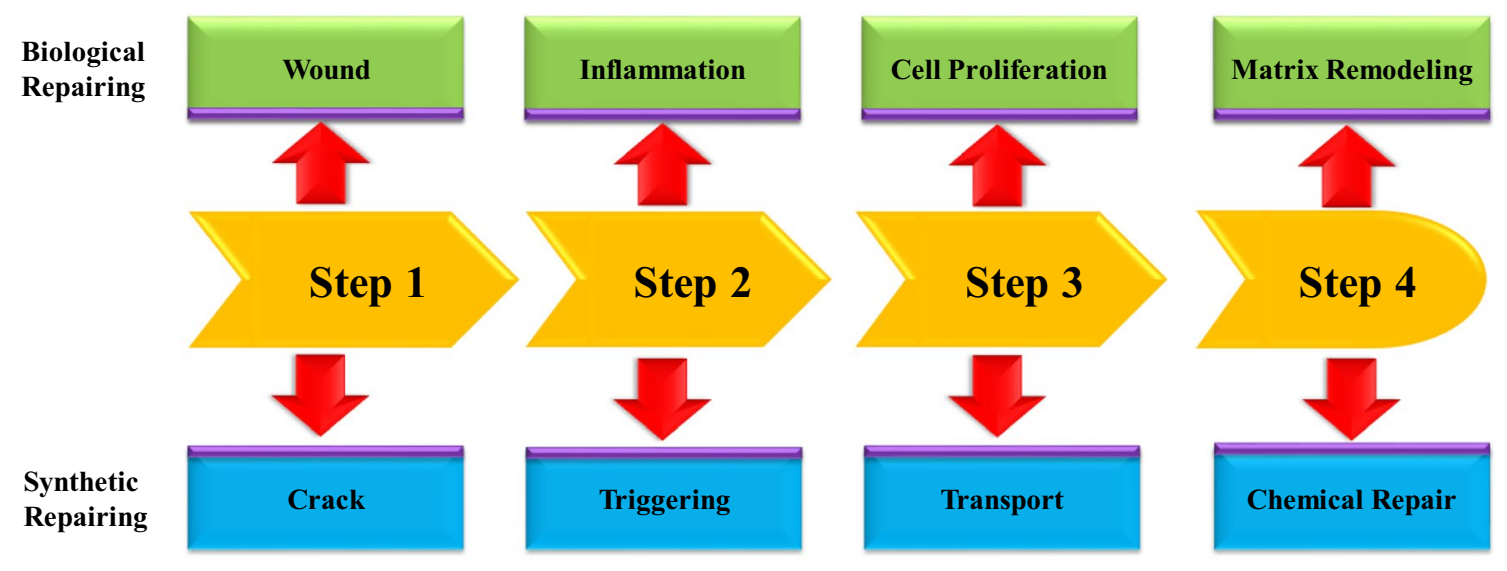

Fig. 1 Step by step comparison of natural self-healing process in living organisms versus synthetic polymers self-healing in polymeric materials from wound/crack to repairing 
agents can encapsulate in different matrices without modification and demands no novelty of the material as in other cases.

\section{Intrinsic self-healing}

Intrinsic self-healing materials, the second generation, are a class of self-triggered materials that autonomically heals after cracks/damage occurs. The basis of intrinsic healing is generally based upon either non-covalent or dynamic covalent chemistries. Non-covalent chemistries include ligand-metal bonding (Zhan et al. 2020), hydrogen bonding (Nie et al. 2020), host-guest interactions (Sinawang et al. 2020 ) and $\pi-\pi$ stacking (Bertran et al. 2020), while Dielalder (Ehrhardt et al. 2020) and radical exchange (Balaji et al. 2020) are examples of dynamic covalent chemistries. The following schematic (Fig. 2) self-explains the progress in the self-healing phenomenon concerning different generations. Where the $3^{\text {rd }}$ and $4^{\text {th }}$ generation can safely be included in extrinsic self-healing owning to nature of the phenomenon.
Self-healing can provide materials long shelf life, improve security, save cost, and on top of all provides sustainable development ( $\mathrm{Li}$ et al. 2019). Looking at different mechanisms of self-healing, i.e. extrinsic and intrinsic, it is clear that intrinsic self-healing is simple in approach without involving external agents, hence any product with intrinsic self-healing would be more precious subjected to fabrication. Moreover, extrinsic self-healing has complexities of pre-embedded processes, sustain and control release, and compatibility of healing agents (Wang et al. 2019d). Reversible cross-links discussed in the next section provides the easy solution, intrinsic in nature, and allow easy fabrication of materials such as through Schiff base bonds which can fabricate and heal at mild conditions (Xu et al. 2019). Other reversible cross-links are discussed briefly as well. To the best of our knowledge, no detailed report on self-healing polymeric materials based on Schiff base bond has been published to date.

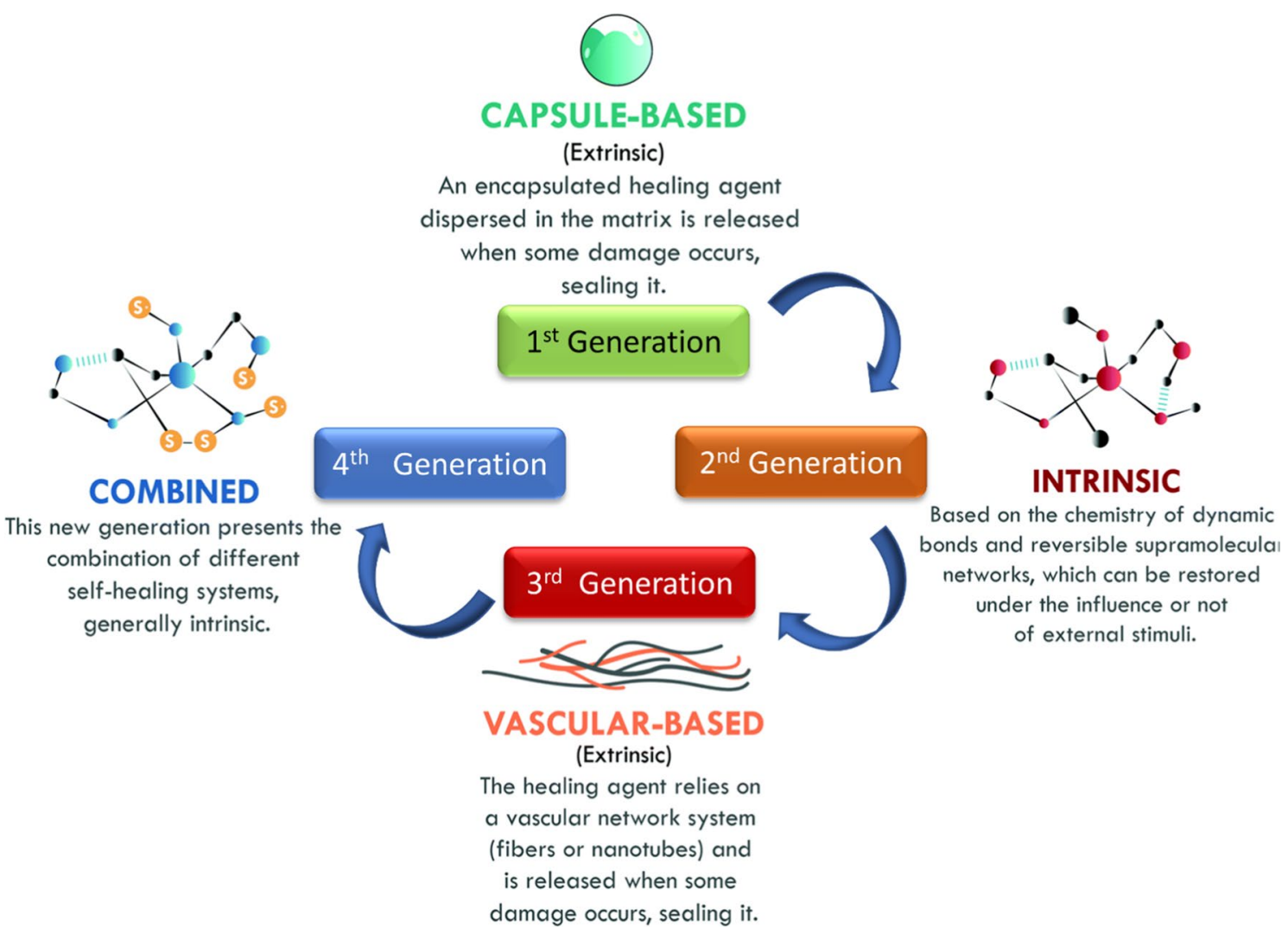

Fig. 2 Detailed representation of different generations of self-healing based upon the healing phenomenon. The successor generations of self-healing in synthetic polymeric materials are described by the mode of healing i.e. extrinsic, intrinsic or a combination of both.
Reprinted from Ref. (Utrera-Barrios et al. 2020) with permission from The Royal Society of Chemistry. Copyright (C) 2020 The Royal Society of Chemistry 


\section{Mechanism of self-healing in reversible crosslinks}

Reversible crosslinks are found in dynamic covalent bonding (Zhang et al. 2018), hydrogen bonding (Zhao et al. 2020), ionic bonding (Wang et al. 2020b), supramolecular (Mohamadhoseini and Mohamadnia 2020), and hydrophobic interactions (Wang et al. 2019b). The degree of selfhealing ability depends upon the number of linkages and strength of moieties. These are important in the design of polymers depending upon their intended applications. Such as, a polymer of physical cross-links employed with weaker interactions is inherently weaker compared with covalently cross-linked networks.

\section{Dynamic covalent bonding}

Dynamic covalent bonds can reform once dismantle, depending upon the condition these bonds can either be reversible as physical non-covalent bonds or as a permanent covalent bond. These consist of imine bonds (Liu and Hsu 2018), disulfide linkages (Grande et al. 2016), acylhydrazone (Zhu et al. 2020), and Diels-alder reactions (Ye et al. 2020) also known as click chemistry (Fig. 3). Yang et al. (2020c) fabricated self-healing vitrimer based on reversible covalent bond using epoxidized soyabean oil and rosin derivativefumaropimaric acid. The developed vitrimer showed excellent self-healing abilities. Jia et al. (2020) using Diels-Alder reaction developed thermoreversible dynamic covalent

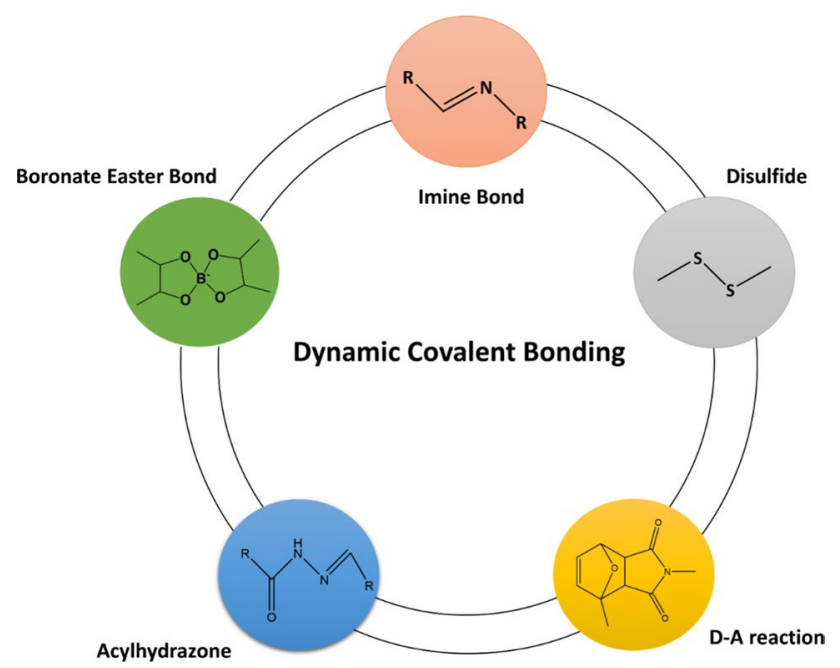

Fig. 3 Different types of dynamic covalent bonding that help in the self-healing phenomenon in polymeric materials along with their chemical structures. Where D-A reaction is abbreviating as DielsAlder reaction. Reprinted from Ref. (Ye et al. 2020) with permission from Elsevier. Copyright (C) 2020 Elsevier bonding based self-healing rubber, this rubber has shown good mechanical properties and self-healing behaviour.

\section{Hydrogen bonding}

Hydrogen bonding introduces self-healing via electrostatic interactions that develop reversible crosslinks between different polymer chains having hydrogen at one side and electronegative atom at other chains. These physical interactions are weaker than dynamic covalent bonding and ionic crosslinks in comparison (Fan et al. 2020). Chen and Guan (2014) designed a self-healing polymer of amidated carbon fibres via hydrogen bonding using chemically modified amidated carbon fibres and hyperbranched polymers. The polymer has shown rapid self-healing at mild conditions. Tamate et al. (2018) developed micellar ion gel composed of hydrophobic ionic liquid and deblock copolymer. This gel has selfhealing abilities owning to hydrogen bonding block along with deblock copolymer ionic liquid-phobic block. Likewise using the same technique, Luan et al. (2018) developed a polymer matrix with self-healing abilities. They fabricated the polymer composite through the incorporation of functionalized graphene oxide to the hyperbranched polymer via hydrogen bonding. Within $10 \mathrm{~min}$ after self-repairing tensile strength of polymer reached $37 \%$ of original strength.

\section{lonic bonding}

Ionic self-healing in polymer happens when reversible electrostatic interactions of oppositely charged ions occur between polymer chains. This involves a charged chain of either polarity crosslinks with an oppositely charged polymer chain (Deng et al. 2020). Once the network disrupts, these chains with opposite polarity cross-link again, hence causing self-healing (Sun et al. 2020a). However, in certain cases, depending upon experimental conditions, deprotonation may occur resulting in electrostatic repulsion. This unfortunate condition in terms of self-healing hinders selfhealing mechanisms. Najwa Thajudin et al. (2021) prepared self-healing rubber based on the ionic network at room temperature, they engineered this self-healing rubber with reversible metal thiolate ionic bonding. Tian et al. (2020) developed a new kind of self-healing composite via dicationic polymerized ionic liquid. The existence of reversible ionic bonds formed by various cations and anions rendered the self-healing ability to this polymeric system.

\section{Supramolecular interactions}

Supramolecular interactions are a class of interactions differentiated based on non-covalent character; these interactions develop by non-covalent complementary inclusion binding involving two or more chemical species (Mohamadhoseini 
and Mohamadnia 2020). In guest-host interactions, typical supramolecular interactions, and unique structural relationship exists. In polymers, chains guest physically inserted inside the host. As this guest-host interaction held supramolecular assembly together by non-covalent interactions hence form reversible crosslinks which can be exploited as a self-healing mechanism (Sinawang et al. 2020). Ahmadi and Ghanavati (2020) fabricated supramolecular guanine-modified poly(nbutyl methacrylate-co-hydroxyethyl methacrylate) copolymers having self-healing properties utilizing guanine and poly (n-butyl methacrylate). Gao et al. (2020) on the same idea prepared novel supramolecular silk fibroin hydrogel, they used 2-hydroxyethyl acrylate and acryloyl- $\beta$-cyclodextrin via photo-polymerization to fabricate this self-healing hydrogel.

\section{Hydrophobic bonding}

In aqueous media, hydrophobic interactions occur with the aggregation of hydrophobic surfaces or hydrophobes. Hydrophobic interactions can easily reform compact hydrophobic structures, when disturbed quickly reform, hence enabling them capable of self-healing mechanism (Zhang et al. 2020c). Wang et al. (2019b) in the same discipline prepared hydrophobic and self-healing coatings using fluorine-containing nanocontainers and carboxylic acid. The hydrophobicity was endowed by fluorinated polymer nanocontainers, which further render self-healing abilities. Sun et al. (2020b) while working on the same concept developed super-hydrophobic hierarchical surfaces polymer utilizing polydimethylsiloxane and carbon black. The microscopic and spectroscopic analysis confirmed the self-healing abilities.

After a substantial study of different self-healing mechanisms, it has been observed that reversible covalent interactions are fastest in terms of reactions and healing in comparison with other corresponding mechanisms, specifically Schiff base bond is very attractive being reversible covalent bond and the reason that it does not need any external stimuli to trigger the healing mechanism (Tseng et al. 2015). Furthermore, Schiff base bond is stronger than other reversible covalent bonds like acylhydrazone and disulfide bonds (Talebian et al. 2019). They exhibit fast reaction speeds and mild reaction temperatures (Ren et al. 2020). These properties make Schiff base bond most suitable among other reversible covalent bonding counterparts.

\section{Schiff base bond based self-healing materials}

Schiff bases are named after Hugo Schiff who synthesized the member of this group for the first time in 1864 (Schiff 1864). Schiff base bond is formed by the condensation reaction of primary amine $\left(-\mathrm{NH}_{2}\right)$ with a carbonyl $(-\mathrm{C}=\mathrm{O})$ or an aldehyde/ketone group. It is a vital reaction as it renders the self-healing ability to the polymer composites. When the polymer is subjected to crack/damage it recombines the internal network and rejoins the chain healing polymer. Schiff base bonds are among rare dynamic reversible bonds having superior properties of giving selfhealing ability without stimuli (Lei et al. 2015). Amine groups are present in different compounds either natural, naturally derived, or non-natural compounds, where the presence of the imine group has been figured out to be imperative in their functionalities (Da Silva et al. 2011).

\section{Self-healing hydrogels}

Hydrogels are hydrated porous media three-dimensional (3-D) polymeric materials having hydrophilic structures (Chai et al. 2017). Hydrogels have received great attention during the past 50 years because of their wider range of applications and because of the possession of flexibility in their nature and resemblance to the natural tissues. These are soft and can mimic the living species thus are highly favourable in regenerative medicines (Slaughter et al. 2009). Further applications of hydrogels are in the scaffold (Spicer 2020), injectable hydrogels (Liang et al. 2019a), nanogels, thin films, and wastewater treatment (Kalia 2016). Self-healing hydrogels are a class of hydrogels having self-healing capabilities, these can be prepared via dynamic covalent bonds and non-covalent interactions (Liu and Hsu 2018). Li et al. (2020a) developed a facile strategy to fabricate modified hyaluronic acid hydrogel blending with cystine. The hyaluronic acid was oxidized to have pendant aldehyde groups before blending.

The hydrogel demonstrated magnificent self-healing properties which were ascribed to the Schiff base linkage formed between hyaluronic acid and cystine, the self-healing ability shown $\sim 100 \%$ efficiency in ten minutes only. Sharma et al. (2020) fabricated a self-healing hydrogel membrane using chitosan, a polymer with various amine groups, with cuminaldehyde as a cross-linker. The Schiff base bonds formed between the chitosan and aldehyde groups of cuminaldehyde. They fabricated a series of hydrogels with varying concentration of cross-linker from 6 to $10 \mathrm{mmol}$ hence having different cross-linking densities. Hydrogel showed magnificent self-healing within a minute; the self-repairing was due to the imine linkages formed between polymer and cross-linker. This hydrogel was expected to have various applications in wound healing, coating, and tissue engineering.

Self-healing polymers are often criticized for their mechanical strength issues. To overcome this trade-off that has always limited the utilization of these self-healing hydrogels, Ding et al. (2020) fabricated acrylamide-modified 
chitosan crosslinking with polyvinyl chloride and oxidized alginate. This blend made an interpenetrating polymer network. The formation of Schiff base was confirmed by Infrared spectroscopy and X-ray photoelectron spectroscopy. Moreover, hydrogel showed that it can self-heal $100 \%$ when incubated for $12 \mathrm{~h}$ without the external stimulus. The selfhealing ability was monitored through optical photographs as different coloured semi-circular plates of hydrogel were place together after cutting in two parts, the cut-off surfaces contacted cleanly showing remarkable self-healing (Fig. 4).

Rahmani and Barzegar (2020) developed dynamic amphiphilic self-healing hydrogel using a series of reactions for the synthesis of different precursors used in the hydrogel. First of all, dibenzaldehyde-terminated telechelic poly (ethylene glycol) (PEG-DA) was fabricated using the one-pot method. Secondly, 4-arm star-shaped polycaprolactone tetraaldehyde (4sPCL-TA) was fabricated. Then, via Schiffbased linkage chitosan, PEG-DA, and 4sPCL-TA solutions were mixed to form self-healing hydrogel. Results indicated successful self-healing without any stimulus externally. The visual method was used to study the self-healing abilities, two discs with different colours were put on one another. The discs become integral within 20 min showing good self-healing. Furthermore, a hole was punched between the Chitosan/PEG-DA/sPCL-TA hydrogel's boundary that was noticed to diminish soon confirming the self-healing properties of the hydrogel.

Using a chemical modification of N,N'-diallyltartardiamide, Wolfel et al. (2020) developed new self-healing hydrogels. They introduced the $\alpha$-oxo-aldehyde functional groups into the $\mathrm{N}, \mathrm{N}^{\prime}$-diallyltartardiamide chain and reacted with 2-aminoethyl methacrylate hydrochloride. Co-existence of N,N'-diallyltartardiamide and 2-aminoethyl methacrylate hydrochloride in the same network endowed the hydrogel self-healing capabilities because of Schiff base bond formation between primary amine and aldehyde groups of $\mathrm{N}, \mathrm{N}$ '-diallyltartardiamide. The hydrogel showed remarkable self-healing capabilities. Liu et al. (2020a) used a new type of cross-linker to fabricate self-healing hydrogel membrane of chitosan. They oxidized debranched starch to dialdehyde debranched starch for introducing aldehyde groups on a debranched starch chain as aldehyde groups are key to make Schiff base linkages. Hydrogel having remarkable self-healing properties was prepared via crosslinking aldehyde debranched starch crosslinking agent with chitosan, Schiff base bonds formed between the aldehyde groups of aldehydes debranched starch and amine groups of chitosan. Scanning electron microscopy of the hydrogel showed the presence of 100-200 nm microgels in a polymeric network of the hydrogel.

Lin and Hsu (2020) used a unique technique to fabricate Schiff base bond hydrogel membrane of chitosan crosslinking with novel nanoparticles of difunctional polyurethane. They used an environment-friendly waterborne process using glyoxal to synthesis biodegradable nano-particle having aldehyde groups. These nanoparticles were used to crosslink chitosan, representing a new platform for crosslinking of macromolecules with nano-particles via dynamic Schiff base reaction. These reversible dynamic covalent linkages between difunctional polyurethane and chitosan produced self-healing hydrogel membranes at ambient conditions and cryogels at $-20{ }^{\circ} \mathrm{C}$, respectively. Rheological characterization confirmed their self-healing capabilities $(\approx 100 \%$
Fig. 4 Visual and structural representation of self-healing process happening in synthetic semi-circular hydrogels made up of acrylamide-modified chitosan (AMCS7), 50\% oxidized alginate (ADA50) and polyvinyl chloride (PVA). Reprinted from Ref. (Ding et al. 2020) with permission from Elsevier. Copyright (c) 2020 Elsevier

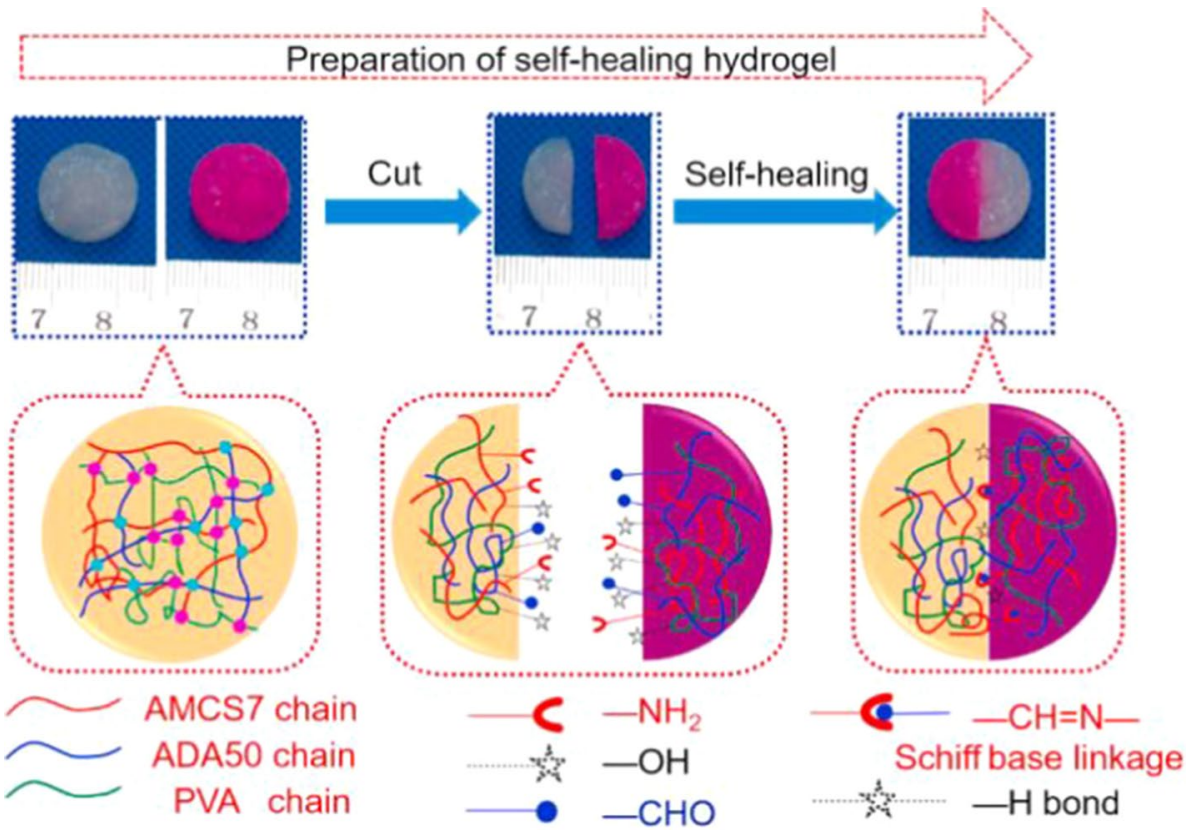




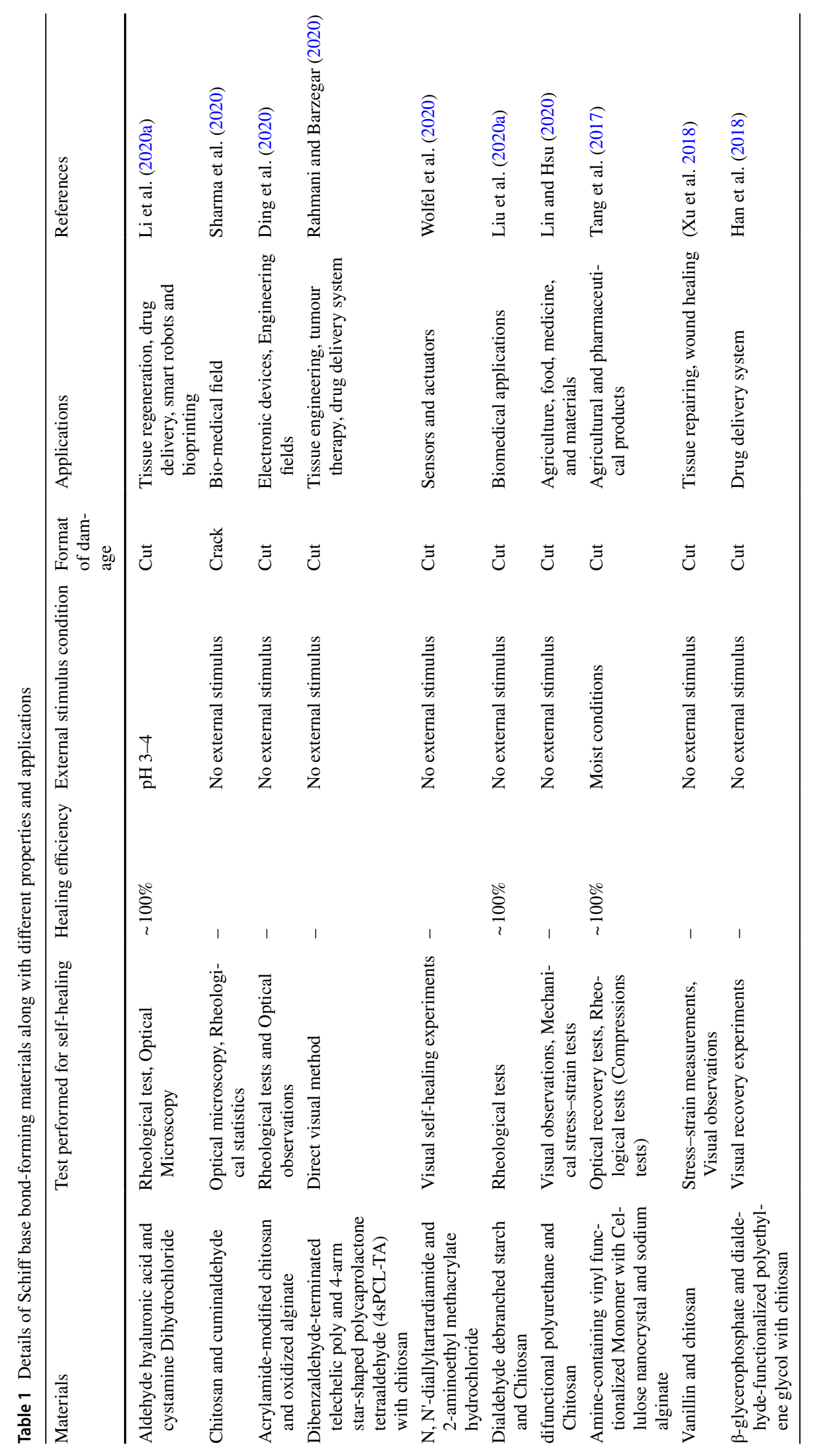


restoration). The comparison with other hydrogels is listed in Table 1.

Green and facile methods of material synthesis have always been attractive. Tang et al. (2017) developed self-healing hydrogels using this approach of cellulose nanocrystals and sodium alginate. The method was organic solvent-free, facile and eco-friendly. Modification and polymerization of polymers conducted in an aqueous solution. To introduce the aldehyde groups, both alginate and cellulose nano-crystals were first oxidized and then blended with polyacrylamide. Through Schiff base reaction aminecontaining monomers were introduced on the cellulose nanocrystals' surface. In one-pot, in situ synthesizes of this bio-hydrogel the sodium alginate and cellulose nanocrystals acted as a macro-cross linker. This physical linkage gave mechanical strength and structural integrity to the hydrogel. The hydrogel shown self-healing at room temperature for several hours.

Likewise, Xu et al. (2018) successfully fabricated selfhealing hydrogel membranes based upon Schiff base linkages of chitosan and natural food flavour vanillin. Chitosan, when cross-linked with vanillin formed Schiff base bonds between imine groups of chitosan and aldehyde group of vanillin and hydrogen bonds between the hydroxyl group and vanillin and the amine group of chitosan. The self-healing property of this hydrogel was originated mainly from the reconstruction of the dynamic Schiff base bond, whereas hydrogen bond was comparatively stable at ambient conditions shows the stress-strain graph of the chitosan-vanillin hydrogel, the hydrogel recovers mechanical strength and stretching properties at mild conditions within $5 \mathrm{~h}$, confirming the excellent self-recovery (Fig. 5).

Han et al. (2018) developed thermosensitive self-healing hydrogel based upon Schiff base bonds crosslinking chitosan with $\beta$-glycerophosphate and dialdehyde-functionalized polyethene glycol. The hydrogel showed autonomous self-healing upon crack/damage and maintained a steady release of doxorubicin hydrochloride. The healing capability was tested successfully in vivo and in vitro by observations as the hydrogel fused and rejoined. Due to the in situ gelling and injectability, injectable hydrogels have gained immense attention recently. Injectable hydrogels are simple in operation, reduces patients' discomfort, risk of injection, treatment cost, and fast recovery times. Once the injectable hydrogel is implanted, it has to cope with mechanical stresses due to body motion, which may deteriorate the polymeric network. That is where self-healing is required, self-healing injectable hydrogels can self-integrate and fix this important issue (Tu et al. 2019). Injectable hydrogels originate from polysaccharide has received extensive attention owing to their distinctive properties of adjustment to irregular wound exterior and minimal invasion.

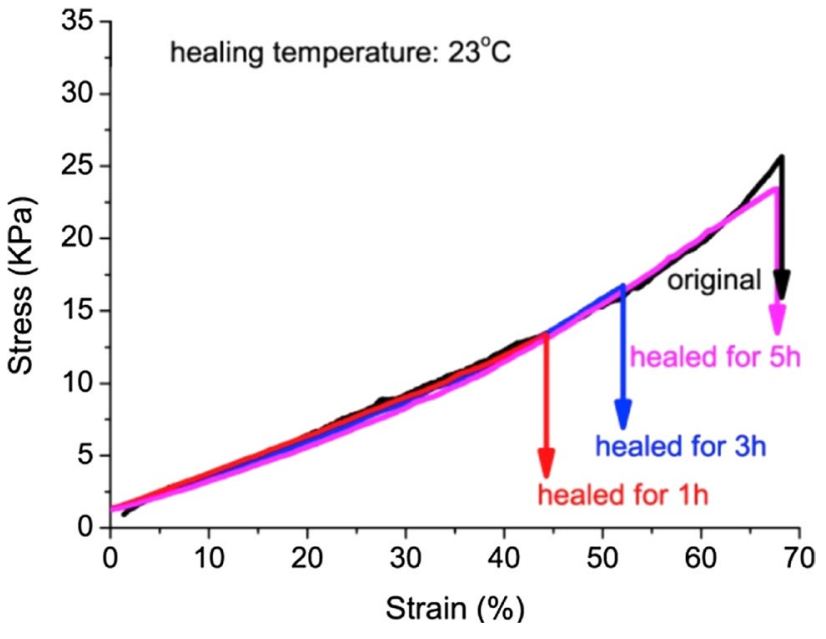

Fig. 5 Compression tests for self-healing evaluation of chitosan/vanillin hydrogel with different timings of self-healed samples, i.e. after $1 \mathrm{~h}, 3 \mathrm{~h}$ and $5 \mathrm{~h}$ at room temperature represented in different colours. The stress versus strain values suggesting improvements in strength from 1 to $5 \mathrm{~h}$ duration. The virgin sample strength is shown with black colour compared to samples after self-healing shown in red $(1 \mathrm{~h}$ after self-healing), blue ( $3 \mathrm{~h}$ after self-healing) and pink ( $5 \mathrm{~h}$ after self-healing). Reprinted from Ref. (Xu et al. 2018) with permission from Elsevier. Copyright (C) 2018 Elsevier

Ehrhardt et al. (2020) used the idea to fabricate hybrid $\mathrm{N}, \mathrm{O}$-carboxymethyl chitosan with chondroitin sulphate. N, O-carboxymethyl chitosan hydrogels were readily developed varying the concentration ratio of both precursors. The formation of Schiff base bond occurred between imine group of N, O-carboxymethyl chitosan, and -CHO group of chondroitin sulphate (Table 2) giving them the ability to self-heal after dismantle. Wang et al. (2020a) developed fluorescent Pluronic $®$ F-127 (EO100-PO65-EO100)-CHO polycitratepolymine-rhodamine B-Carboxymethyl Chitosan hybrid hydrogel system (FPRC) injectable hydrogel with selfhealing capabilities. The Schiff base was formed between Pluronic ${ }^{\circledR}$ F-127 (EO100-PO65-EO100)-CHO, polycitratepolymine-rhodamine $\mathrm{B}$ polymer, and Carboxymethyl Chitosan. These hydrogels have shown multifunction including self-healing which revealed its roots in dynamic Schiff base bonds. Another multifunction injectable hydrogel system was fabricated by Ehrhardt et al. (2020). They developed carboxymethyl chitosan-mixed carbon quantum dots with oxidized dextran as injectable drug release hydrogel. The network linked through Schiff base linkages inheriting them the self-healing abilities with stretchable and biofilm making capabilities. In anti-cancer drug delivery, $\mathrm{pH}$-sensitive hydrogels with self-healing properties are potentially great.

Zhan et al. (2020) developed such self-healing injectable hydrogels using N-carboxyethyl chitosan and Polyethylene glycol triethylolpropane ether (4 armPEG)-benzaldehyde. The Schiff base linkages were formed between 4 


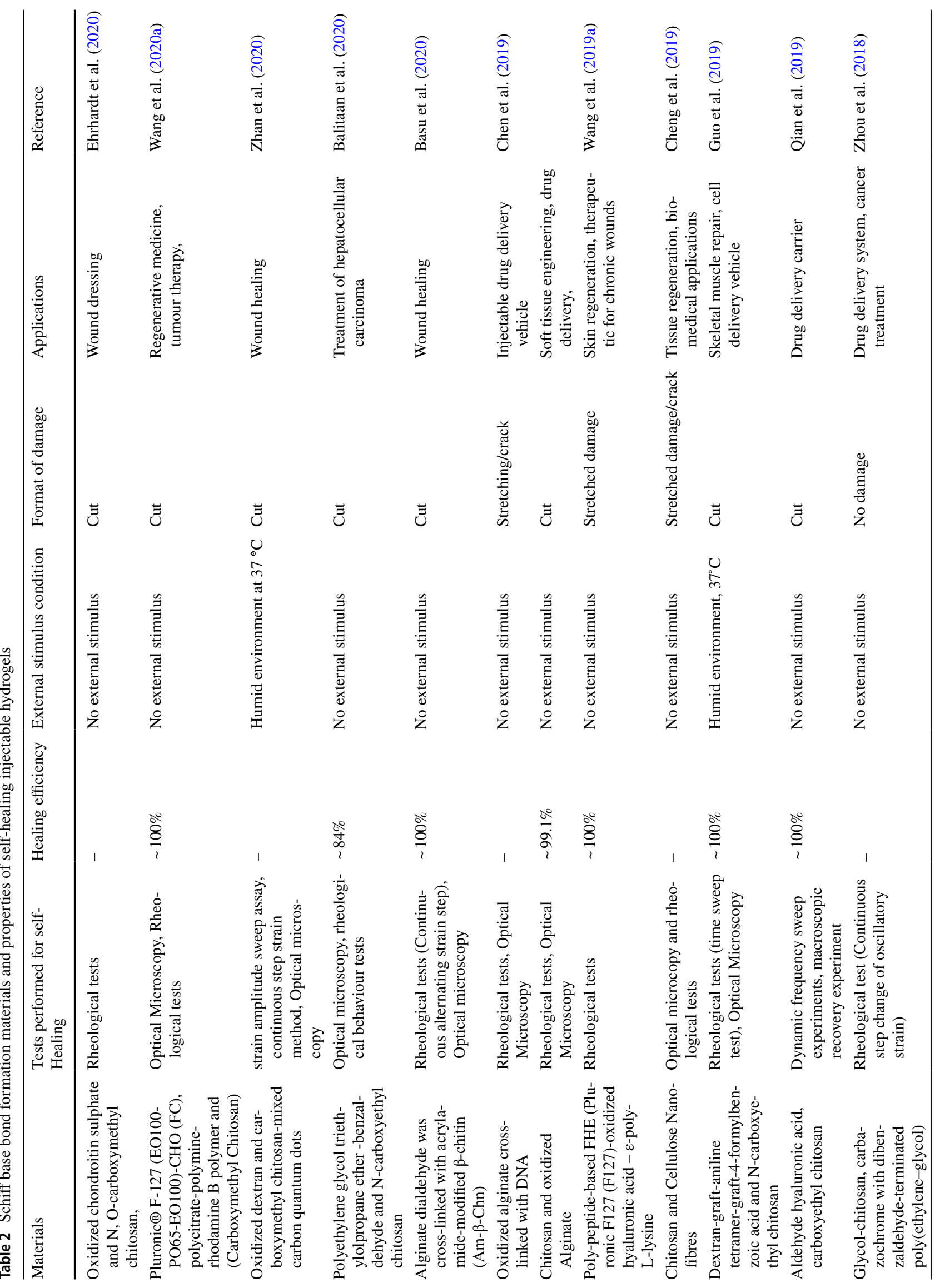



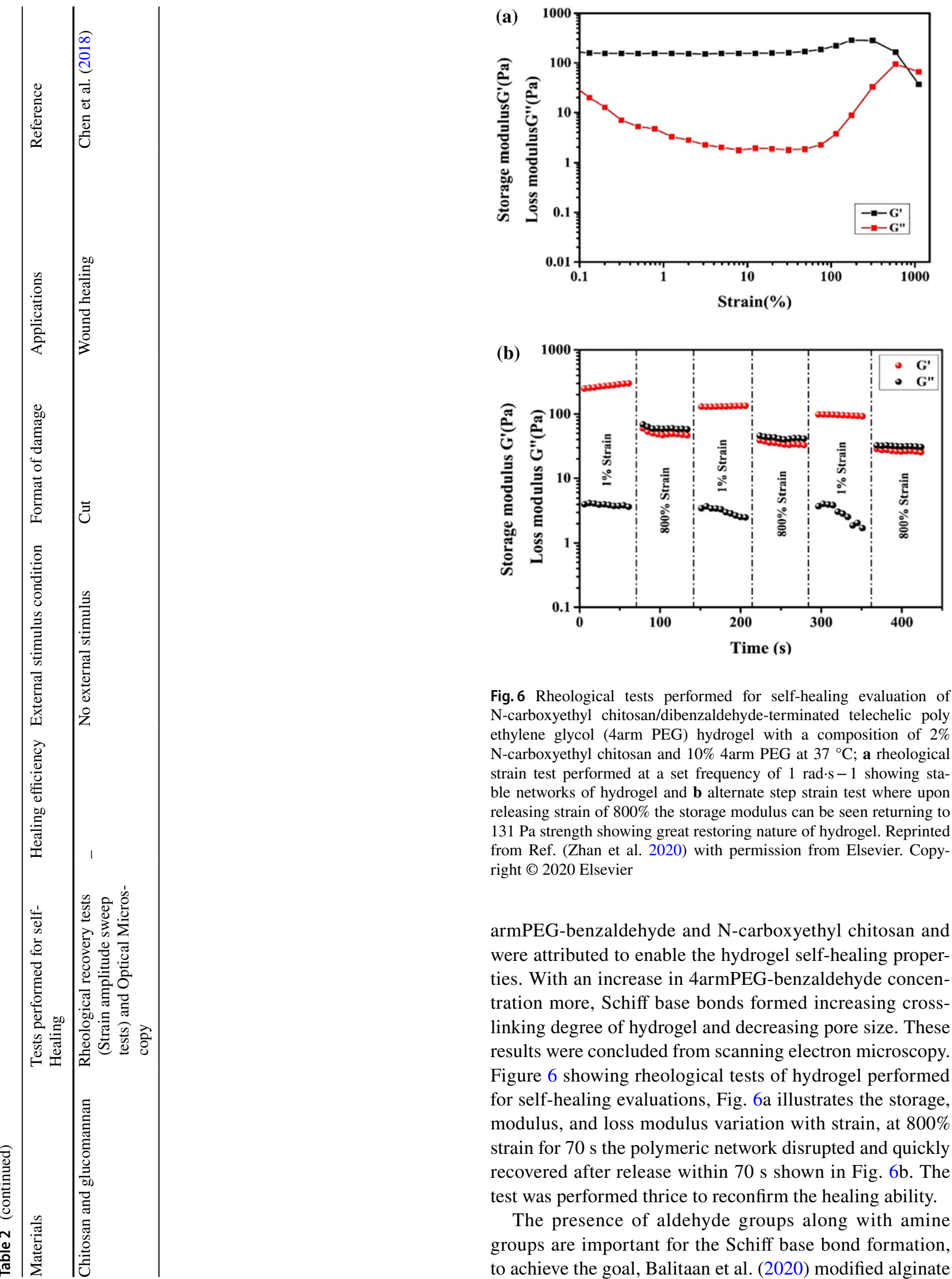

Fig. 6 Rheological tests performed for self-healing evaluation of $\mathrm{N}$-carboxyethyl chitosan/dibenzaldehyde-terminated telechelic poly ethylene glycol (4arm PEG) hydrogel with a composition of $2 \%$ $\mathrm{N}$-carboxyethyl chitosan and $10 \%$ 4arm PEG at $37{ }^{\circ} \mathrm{C}$; a rheological strain test performed at a set frequency of $1 \mathrm{rad} \cdot \mathrm{s}-1$ showing stable networks of hydrogel and $\mathbf{b}$ alternate step strain test where upon releasing strain of $800 \%$ the storage modulus can be seen returning to $131 \mathrm{~Pa}$ strength showing great restoring nature of hydrogel. Reprinted from Ref. (Zhan et al. 2020) with permission from Elsevier. Copyright (C) 2020 Elsevier

armPEG-benzaldehyde and N-carboxyethyl chitosan and were attributed to enable the hydrogel self-healing properties. With an increase in 4armPEG-benzaldehyde concentration more, Schiff base bonds formed increasing crosslinking degree of hydrogel and decreasing pore size. These results were concluded from scanning electron microscopy. Figure 6 showing rheological tests of hydrogel performed for self-healing evaluations, Fig. 6a illustrates the storage, modulus, and loss modulus variation with strain, at $800 \%$ strain for $70 \mathrm{~s}$ the polymeric network disrupted and quickly recovered after release within $70 \mathrm{~s}$ shown in Fig. 6b. The test was performed thrice to reconfirm the healing ability.

The presence of aldehyde groups along with amine groups are important for the Schiff base bond formation, to achieve the goal, Balitaan et al. (2020) modified alginate 
and $\beta$-chitin. Alginate dialdehyde was cross-linked with acrylamide-modified $\beta$-chitin to form Schiff base linkagebased self-healing injectable hydrogels (Fig. 7). The selfintegrating properties were assessed by rheological and microscopic observation. Continuous alternating strain step was performed which shown conforming results that these injectable hydrogels were self-healing.

Basu et al. (2020) developed injectable hydrogel for the delivery of a small molecule drug named simvastatin. They fabricated this self-healing hydrogel using oxidized alginate cross-linked with deoxyribonucleic acid. The Schiff base linkage was developed between deoxyribonucleic acid-oxidized alginate. To regulate the rheological activities of this hydrogel oxidized alginate and silicate-based nanoparticles were used in varying concentrations. Chen et al. (2019) synthesized self-healing, injectable hydrogels of chitosan/alginate encapsulating them with magnetic gelatin microspheres. These hydrogels aimed to deliver anti-cancer agents, magnetic gelatin microspheres, and tissue engineering. The chitosan was linked with oxidized alginate via dynamic Schiff base bond. The hydrogel exhibits great self-healing properties in mild conditions and in vitro sustain drug release.

Following the idea of introducing aldehyde groups in polymer chains to develop dynamic imine linkages with amine groups, Wang et al. (2019a) also adopted the polymer oxidation technique before cross-link. They fabricated injectable hydrogel from poly-peptide-based Pluronic F127 (F127)oxidized hyaluronic acid $-\varepsilon$-poly-L-lysine. The oxidized hyaluronic acid was synthesized from hyaluronic acid oxidation with sodium periodate, oxidation of hyaluronic acid was done to introduce aldehyde groups. This hydrogel was demonstrated to be multifunctional like $\mathrm{pH}$-responsive, antibacterial, injectable, shear-thinning and self-healable. Injectable hydrogels are known to be impactive in tissue repairing, being attractive materials for tissue repairing, these were never demonstrated in the mentioned field. To cope with the challenge Cheng et al. (2019) developed novel chitosancellulose nanofiber composite hydrogels with autonomous repairing abilities. Formation of Schiff base bonds occurred between chitosan-cellulose nanofiber and Chitosan endowing self-healing abilities. To demonstrate self-healing, the hydrogel was extruded through 160 microns diameter needle, the hydrogel passed without clogging. Furthermore, the central hole of $0.5 \mathrm{~cm}$ diminished in a few hours, and hydrogel recovered completely proving the self-healing abilities.

For skeleton muscle regeneration, injectable hydrogels are believed to be used as transport vehicles, Guo et al. (2019) used this idea to fabricate injectable self-healing hydrogels using dextran-graft-aniline tetramer-graft-4-formylbenzoic acid and N-carboxyethyl chitosan. These polymers were mixed at physiological conditions making Schiff base bond between N-carboxyethyl chitosan and formyl benzoic acid. These mighty linkages gave, thus, formed hydrogel membrane self-healing privileges. For self-healing strain amplitude sweep test was performed. The outcome has shown that after high strains, damaged hydrogel recovered quickly and rapidly confirming the self-healing nature. Materials based on facile and green synthesis are always preferred in the medical application of materials, Qian et al. (2019) used a facile and green method to fabricate injectable hydrogel having self-healing abilities. This multifunctioning hydrogel was based on polysaccharides. The aldehyde hyaluronic

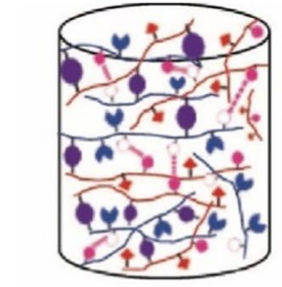

pristine

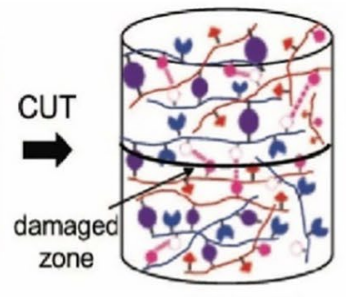

damaged

Am- $\beta$-Chn/ADA hydrogel Am- $\beta-C h n / A D A$ hydrogel

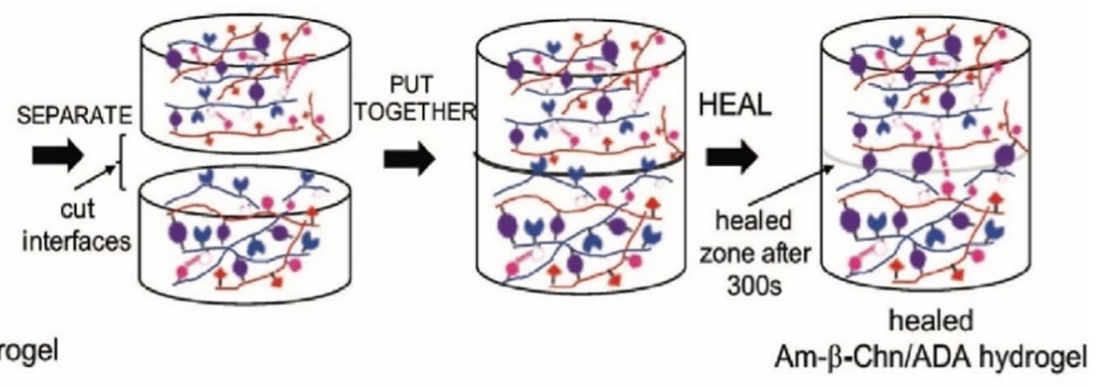

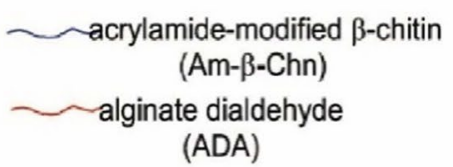

(ADA)

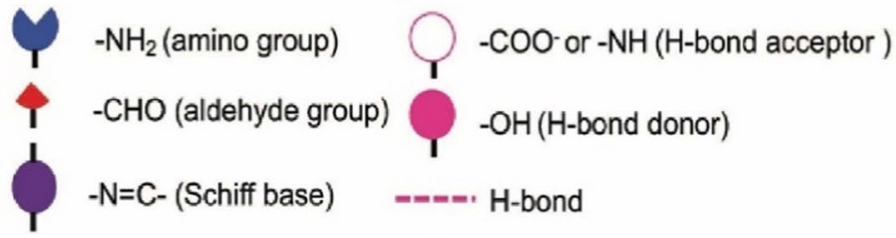

Fig. 7 Self-healing mechanism in acrylamide-modified $\beta$-chitin/ alginate dialdehyde (Am- $\beta$-Chn/ADA) hydrogels. From left to right, first step showing the pristine sample, the second step showing damage being done, the third step illustrating the cut-off hydrogel in two pieces, the fourth step piece showing reunion of cut-off hydrogel pieces and the fifth step is visualizing the self-healing sample after 300 s. Furthermore, self-healing phenomenon through structural representation is also presented. Reprinted from Ref. (Balitaan et al. 2020) with permission from Elsevier. Copyright (c) 2020 Elsevier 
acid was physically cross-linked with carboxyethyl chitosan. The self-healing was attributed to the formation of Schiff base bonds developed from imine groups of carboxyethyl chitosan and aldehyde groups of aldehyde hyaluronic acid. Zhou et al. (2018) developed a three-component systemdependent self-healing injectable hydrogel having dynamic Schiff base bond. With imine linkages glycol-chitosan and carbazochrome having amine groups physically cross-linked with dibenzaldehyde-terminated poly(ethylene-glycol). The reaction was carried out at physiological conditions within $200 \mathrm{~s}$.

Using novel hydrogel material, Chen et al. (2018) fabricated injectable hydrogel having potential applications in wound healing (Table 2). Self-healing hydrogel was designed using chitosan and glucomannan. The glucomannan was oxidized before reacting with chitosan. Chitosan was physically cross-linked with oxidized glucomannan to develop hydrogel. The hydrogel besides having self-healing abilities shown biocompatibility, antibacterial activity, and adhesive properties. To judge the self-healing capabilities, both optical microscopy and rheological tests were performed. In optical observance, different hydrogels with differently dyed colours were cut off and placed together which shown self-healing visually. In rheological tests, strain amplitude sweep tests were performed. The rheological tests have shown that this hydrogel can heal within $4 \mathrm{~h}$ without interruption from external stimuli.

\section{Elastomers}

Properties like mechanical strength, flexibility, and selfhealing always add more value to polymers like elastomers, especially when we are using them in high technological fields. Holding the idea of multi-functioning elastomer, Zhang et al. (2020b) developed a three-dimensional network via three effective reactions. They used polydimethylsiloxane $(\mathrm{Mn}=2000)$ terminated with $\alpha$, $\omega$-aminopropyl to develop this network via Schiff base and dehydration reaction. The developed elastomer showed very good properties like mechanical strength of $2.54 \mathrm{MPa}$ tensile strength with $257.3 \%$ at break average elongation. The elastomer was endowed self-healing ascribed to dynamic Schiff base and hydrogen bonds. Self-healing efficiency of $91.6 \%$ was achieved at mild conditions, $95.1 \%$ at high temperature, and $85.5 \%$ in water (Table 3 ). Self-healing abilities in service coupled with recyclability while disposing of materials is a challenging task in the rubbers and thermosets material field, Ye et al. (2020) took the challenge and fabricated novel self-healing silicone elastomers with both mentioned properties.

The novel elastomer was designed by incorporating Schiff base linkage having excellent recyclability and self-healing. Two steps were performed during preparation; first, dimethylsiloxane cyclic tetramer and 3-aminopropyl(diethoxy) methylsilane were copolymerized to prepare aminopropyl-polydimethylsiloxane. Second, aldehyde group pendants on aminopropyl-polydimethylsiloxane were reacted with 1,4-phthalaldehyde. These back-to-back processes made Schiff base linkage-based aminopropylpolydimethylsiloxane elastomer, having two imine bonds with a benzene ring. The self-healing of elastomer was assessed by commonly used visual microscopic observation test and tensile strength tests before and after repair (Table 3). It was observed that after $6 \mathrm{~h}$ of self-healing tensile strength was $0.09 \mathrm{MPa}$ and restored to $50 \%$ of initial strength and $94 \%$ after $24 \mathrm{~h}$. One of the prepared samples shown $95 \%$ healing at room temperature. Wearable devices and electrical skin need materials with high stretchable and self-healable qualities, Yang et al. (2020c) proposed such material based on a one-pot two-step approach to develop polydimethylsiloxane elastomers. Polydimethylsiloxane was fabricated via two steps, first, by reacting excess aminopropyl terminated polydimethylsiloxane with isophorone diisocyanate to produce amino-terminated polydimethylsiloxane incorporated with ureido groups. Second, reacting it with terephthalaldehyde that yields self-healing PMDS elastomer at $25{ }^{\circ} \mathrm{C}$. The auto-healing of this elastomer was attributed to hydrogen bonds, dynamic Schiff base linkage, and high flexible $\mathrm{Si}-\mathrm{O}$ chains. The self-healing achieved by elastomer after $24 \mathrm{~h}$ of repairing was $95 \%$ and shown a high stretchability of $1670 \%$.

Another silicon elastomer having adjustable mechanical and self-healing properties was developed by Jia et al. (2020). They prepared the elastomer by crosslinking 4,4'-methylenebis-(cyclohexyl isocyanate) and isophthalaldehyde sequentially with aminopropyl terminated polydimethylsiloxane. The bonds detected to be participating in self-healing were imine bond and urea groups. The elongation of his polymer was in the range of $700-800 \%$ at a break point. Mechanical dynamic analysis, optical microscopy, and rheological tests were conducted to assess the self-healing abilities that yield $100 \%$ efficiency at $25^{\circ} \mathrm{C}$. The idea that dynamic imine undergoes recoupling properties under physiological conditions when used as chain extender or crosslinked helped Bui and Brook (2019) designing various elastomers with self-healing abilities. Schiff base linkagebased polysiloxanes elastomers were synthesized by reacting aromatic aldehydes with aminopropyl-functionalized polydimethylsiloxane.

\section{Coatings and adhesives}

Everyday life demanding products like adhesives are essentials and their demand is increasing (Ghaffar et al. 2014), to cope with this crucial and growing demand of adhesives various materials have been designed with 


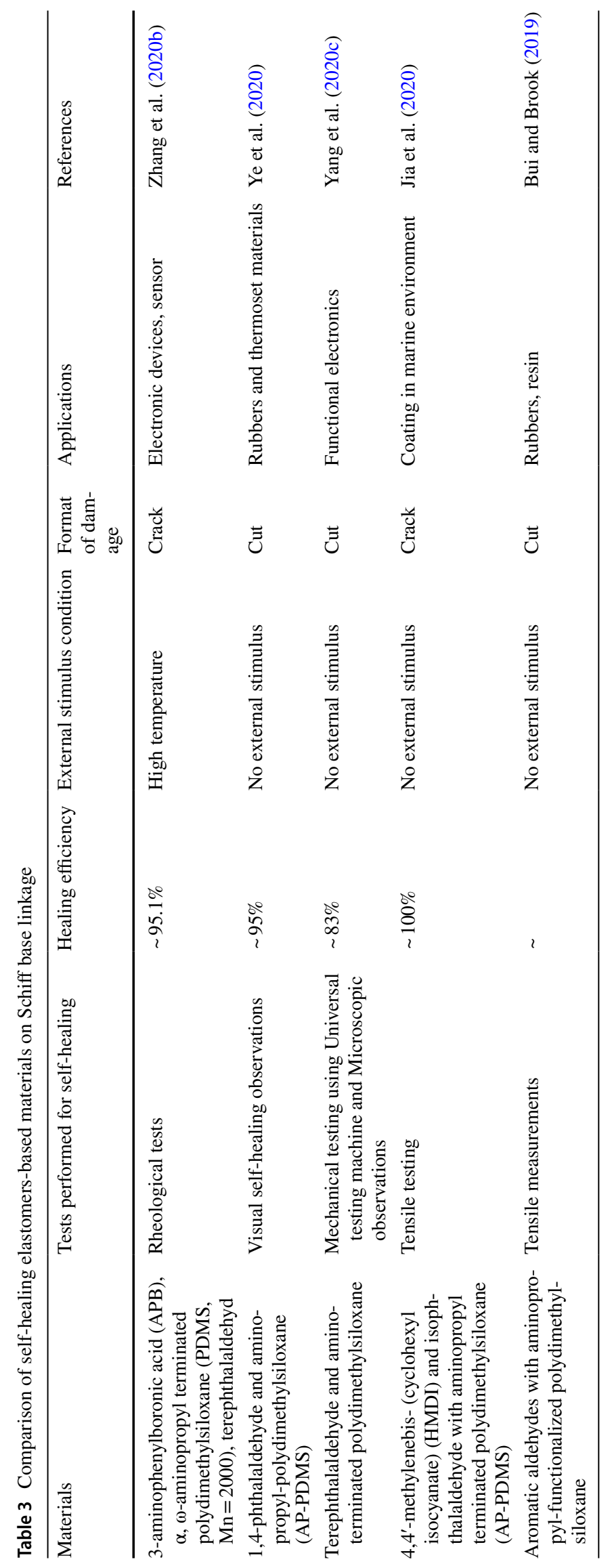


adhesion properties like thermoplastics and thermosetting polymers. However, adhesives based on reversible covalent bonds can repair themselves which increases not only their service life but also their demand. Based on this unique property of these adhesives, they got an attraction in recent years (Tang et al. 2017). Knowing the importance of selfhealing-adhesives and their growing market demand Gong et al. (2020) developed self-healing adhesives based on Schiff base chemistry and addition-fragmentation chain transfer (RAFT) polymerization. Firstly, an esterification reaction was run to synthesize ethylcellulose having a basis on macroinitiators. Second, grafting from RAFT of lauryl methacrylate and vanillin methacrylate was exploit to get graft copolymer. The self-healing tests showed that the healing efficiency was $98.7 \%$ (Table 4) and mechanical strength $0.81 \mathrm{MPa}$.

Using lignin to produce dynamic networks having multipurpose and multifunctional viable applications, Gao et al. (2020) fabricated self-healing, conductive and antifungal adhesives. They combined dynamic chemistry with grafting from reversible addition-fragmentation chain transfer (RAFT) polymerization to develop a dynamics network of lignin. Through RAFT polymerization vanillin, a form of lignin was structurally reorganized as a building block with a fatty acid-derived compound as co-monomer. It was revealed that the properties of these fabricated adhesives were tunably subjected to the polymerization conditions. Due to the existence of aldehyde groups from vanillin, the reversible network was formed utilizing diamines as chain-extender. The rheological tests checked the self-healing capabilities confirming that self-healing reached $83.1 \%$ with a mechanical strength of $2.9 \mathrm{Mpa}$.

He et al. (2020) fabricated another self-healing adhesive based on Schiff base bond. They developed their adhesive hydrogel using N-carboxyethyl chitosan and benzaldehydeterminated Pluronic F127/carbon nanotubes (PF127/CNT). The Schiff base bond formed between PF127-CHO and porcine dermal. The adhesive hydrogel showed good selfhealing abilities. Qu et al. (2018) developed adhesive injectable hydrogel based on dynamic Schiff base and copolymer micelle for Joint wound healing. Under physiological conditions, they fabricated a series of hydrogels by blending benzaldehyde-terminated Pluronic $® F 127$ (PF127-CHO) and quaternized chitosan. Macroscopic and rheological tests were conducted to assess the self-repairing abilities (Table 4) of this adhesive hydrogel. In macroscopic observation, hydrogels of same height and diameter were cut and placed together for $2 \mathrm{~h}$ at $25{ }^{\circ} \mathrm{C}$. The hydrogel healed without external intervention proving the self-healing ability.

The development of multifunctional additives has great importance because of their unique properties, especially in surface adjustment. The design of multifunctional additives has greatly improved the functions of novel additives in contrast with the traditional additives; even a low concentration markedly improves mechanical, thermal, self-cleaning, self-healing, and anti-corrosive properties of polymer composites and coatings. Atta et al. (2020) designed multifunctional self-healing and super-hydrophobic steel coating following the same idea. They developed versatile cardanol triazine Schiff base epoxy coatings with self-healing properties for steel coating. In development, cashew oil derived cardanol was reacted with bishydrazino-s-triazine derivative followed by reaction with terephthaldehyde yielding a Schiff base polymer.

Cardanol-bishydrazino-s-triazine-based polymer contained Schiff base that was confirmed by Fourier transform infrared spectroscopy and nuclear magnetic resonance spectroscopy. Self-healing and super-hydrophobic epoxy coatings were produced by more than $3 \mathrm{wt} . \%$ presence of cardanol- bishydrazino-s-triazine polymer. To assess the self-healing ability, the $\mathrm{x}$-shaped cut was observed for a specific time, the cut healed itself showing self-healing properties of the polymer. The existence of amine linkages in the chemical structure was attributed to self-healing abilities. Yang et al. (2020a) prepared self-healing silicon coating based on Schiff-linkages. The silicon coatings purposely inhibiting the adhesion of benthic diatoms. The coating was prepared by synthesizing polydimethylsiloxane polymer followed by adding eco-friendly antifoulant. The polydimethylsiloxane polymer contains urea groups and imine groups, giving it self-healing capabilities. To verify the selfhealing capability, the scratch test was performed (Table 4) and scratch disappeared in less than $3 \mathrm{~h}$, showing excellent self-healing ability.

Ren et al. (2020) prepared a series of different coatings with self-healing abilities consisting of dialdehyde starch cross-linked chitosan with Schiff base linkages. The selfhealing tests were performed for differently mixed $\mathrm{NH}_{2} /$ $\mathrm{CO}$ ratios, the results shown that the best optimised sample shown $96.1 \%$ self-healing. Self-healing properties were recording using optical microscopy, by running water on the damaged part, it made scalpel on imine linkage-based coating, consequently damaged parts came together with each other completely healing. Self-healing was credited to the relinking of dynamic Schiff base linkages, rebuilding the structure. The coatings healed within 10 min showing rapid healing ability. Luo et al. (2020) developed biocompatible self-healing coatings promoting adhesion of coral cells based on Schiff base. Using layer-by-layer self-assembly technique they developed dialdehyde starch modified chitosan Schiff base films. Lysozyme and dopamine were utilized as a modifier of Schiff base films. Scratched were produced on the surface of the film and deionized water was added to let the self-healing process progress in a wet environment. The scratches disappeared in $15 \mathrm{~min}$ after adding the water drops. Lee et al. (2019) developed dual cross-linked polyurethane 


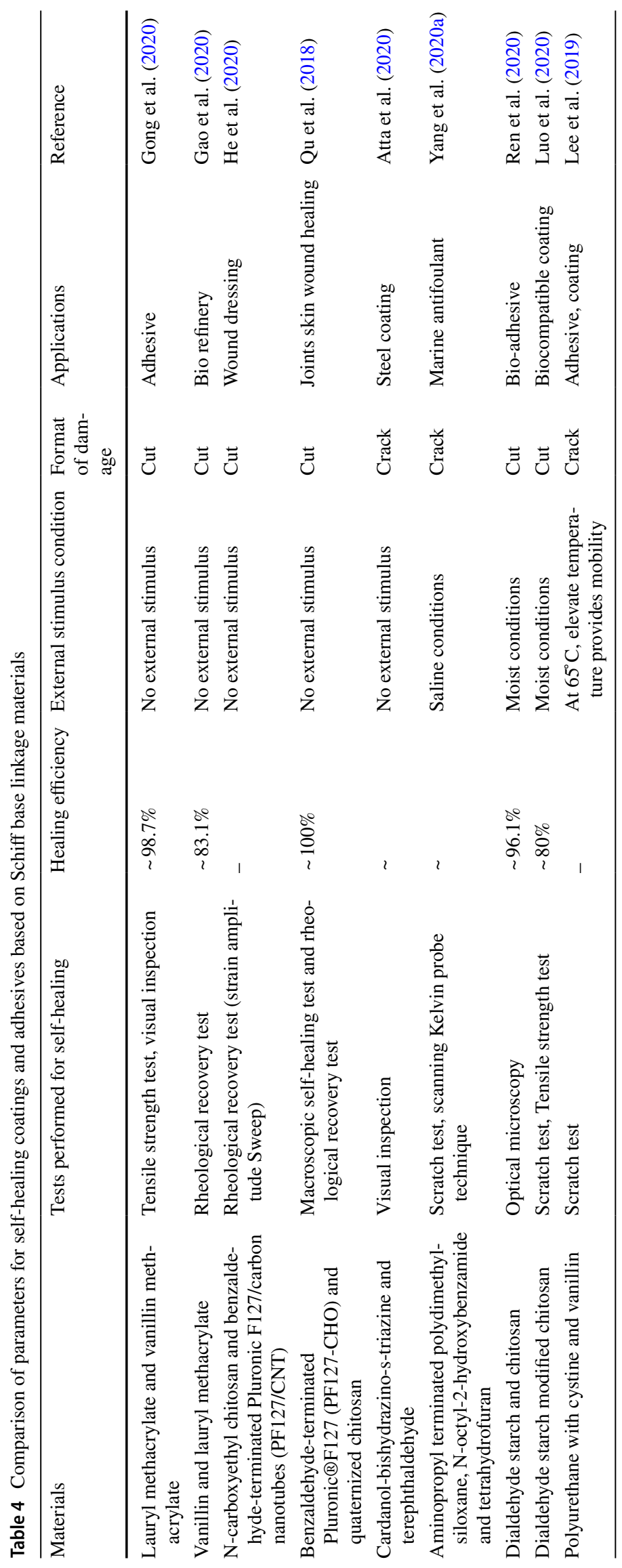


with cystine and vanillin via dynamic Schiff base bond. The fabricated composite showed excellent self-healing under metatheses as a stimulus.

These Schiff and disulfide-based composites were blended with 1,4-butanediol ensuring miscibility besides polyurethane prepolymer. This was then utilized as a crosslinker to establish self-healing and reversibility to crosslink with polyurethane. Crosslink polyurethane in contrast with polyurethane shown less self-healing capability as it has only one dynamic covalent bond that is imine linkage, whereas polyurethane has disulfide and imine linkage both. Polyurethane cross-linked with Schiff base shown remarkable self-healing and recyclability having less activation energy. Schiff base polyurethane has furthermore shown dual-responsive self-repairing by UV-irradiations and heat. To assess the self-healing ability scratch test was performed, a scratch of depth 500 microns was introduced on the surface. The sample was stored at $65^{\circ} \mathrm{C}$ for damage repair, the scratches of Schiff base polyurethane completely healed within 50 min (Fig. 8).

\section{Dimensional printing, electronics and films}

Artificial meniscus implant has been encountered by many failures after transplantation like mechanical failure, patients' specific design, and chondrogenic capability. Gupta et al. (2020) taking the seriousness of the issue fabricated 3D printing scaffold utilizing carbohydrate dependent interpenetrating network. This 3D printing hydrogel-based monolith could load the bearings of meniscus tissue. They synthesized the polymer using collagen, alginate, and oxidized alginate. Interpenetrating network hydrogel was fabricated via dual crosslinking $\mathrm{Ca}^{2+}$ based ionic cross-linking and Schiff base (Alginate-Alginate) ability. To check the self-healing abilities, each hydrogel was coloured differently and cut off followed by putting together to assess the self-healing. The results confirmed the self-repairing ability as polymer merged within $20 \mathrm{~min}$. Ko et al. (2020) successfully fabricated self-healing ferrogels via a facile method. They synthesized these ferrogels by utilizing glycol chitosan and oxidized hyaluronate, the developed ferrogels shown self-healing capabilities in presence of superparamagnetic iron oxide nanoparticles (SPIONs) with physical crosslinks. Using the extrusion printing method, this polymer ferrogel material was successfully fabricated into various 3D shapes.

They tested their self-healing properties through visual and optical microscopy, developed these hydrogels in a cylindrical mould, broken into fragments using mortar and pestle, placed together into the mould. After just $10 \mathrm{~min}$, the ferrogels restored to their original shape. Flexible and self-healing electronics are the need of the hour, to develop such materials based on imine linkage. Yang et al. (2020b) fabricated a skin-inspired electret

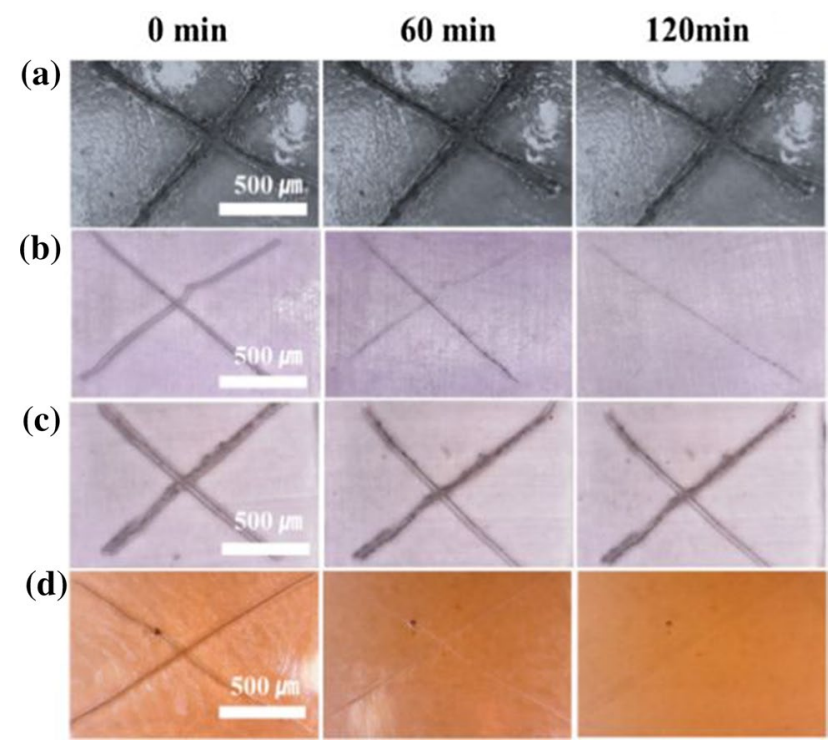

Fig. 8 Optical images of scratch healing test taken after 0,60 and 120 min of self-healing of; a Cross-linked polyurethane, b Crosslink polyurethane mixed with 1,4-butanediol/2-hydroxy disulfide, c Schiff base polyurethane and d prepared polyurethane networks at $65{ }^{\circ} \mathrm{C}$. The fading crossed shaped scratches can be seen confirming the great self-healing abilities of cross-linked networks of polyurethane. Reprinted from Ref. (Lee et al. 2019) with permission from Elsevier. Copyright (C) 2019 Elsevier

nanogenerator. They used $\mathrm{NH}_{2}$ - polydimethylsiloxane $-\mathrm{NH}_{2}$ $\left(\mathrm{NH}_{2}\right.$-polydimethylsiloxane- $\mathrm{NH}_{2}$ ) and tris(4-formylphenoxy) methylethane (TFME) to produce polydimethylsiloxane -TFME composite with self-healing abilities. The healing tests to assess the self-healing properties were in situ observations and mechanical test. The composite film was cut into pieces using a razor blade, placed together along a line of cutting; the composite integrated itself into a single material within $6 \mathrm{~h}$ showing remarkable self-healing abilities (Fig. 9). To further assess, tensile tests were conducted at different healing times. These tests revealed that healing efficiency reached $95 \%$ in $6 \mathrm{~h}$, while the strain of the healed sample reached almost $100 \%$. These Schiff base bonds were attributed to endow the self-healing abilities in the elastomer polydimethylsiloxane -TFME.

Self-healing potential in electronics is very imperative to gain maximum advantage from them, keeping under consideration the importance of self-healing polymer in electronic materials, Liang et al. (2019b) tried to solve the problem of commercial sensors. Commercial sensor lacks durability and reliability because of the fact that glucose oxidase leak along with electrocatalytic medium, glucose penetrates in the dense coating material and vulnerability of sensor to mechanical damage. They fabricated self-healing sensors based on Schiff base bond using Qatarized chitosan and oxidized dextran. As an electrocatalytic medium, $\mathrm{CeO}_{2} / \mathrm{MnO}_{2}$ hollow nanospheres were cross-linked covalently. To gauge 

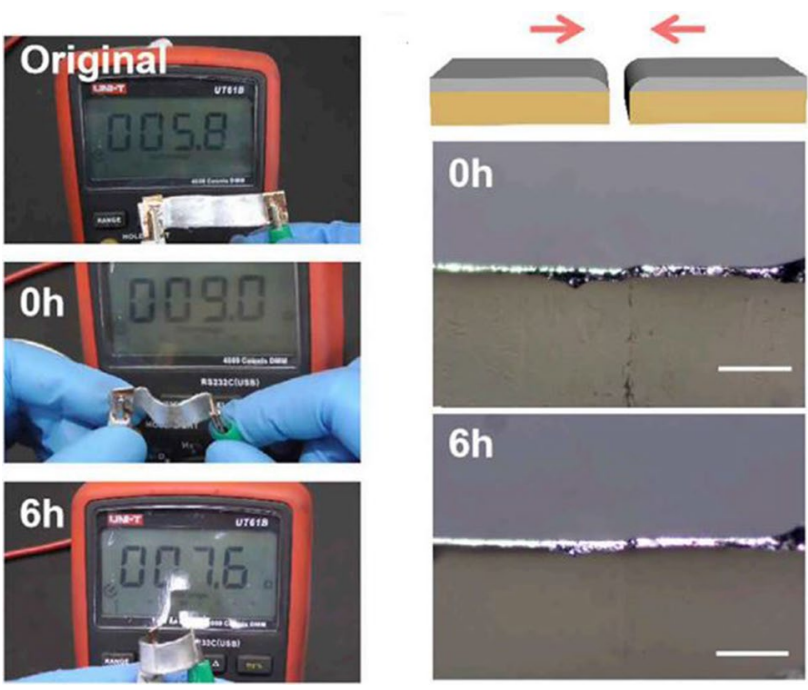

Fig. 9 Self-healing performance via resistance measurement of liquid metal-polydimethylsiloxane film, for the original sample, just after cut $(0 \mathrm{~h})$, and after self-healing for $6 \mathrm{~h}$. Before healing, samples were cut into two parts, after connecting and healing the conduction properties were assessed to evaluate the self-healing efficiency of the synthesized films. The decrease in resistance from 0 to $6 \mathrm{~h}$ confirming the excellent healing properties of the film. Reprinted from (Yang et al. 2020b) with permission from Elsevier. Copyright (C) 2020 Elsevier the self-healing capabilities of the hydrogel, rheological tests were performed which shown confirming results.

Another self-healing polymer based on Schiff base linkages was developed by Liu et al. (2020b). They fabricated this vitrimer with potential applications in sustainable structural applications from vanillin, Bisphenol A diglycidyl ether and m-xylylenediamine. The Schiff base bond formation rendered the vitrimer weldability, remoldability, self-healing and rapid stress relaxation behaviour. To test the self-healing capabilities of this polymer, the vitrimer was scratched with a knife and placed under a polarizing microscope with a hot stage. Under high-temperature conditions, the crack completely disappeared, which made the author conclude that the higher the temperature the better were healing abilities. At higher temperatures, the chains gradually started diffusion which made relink of chains easy. The sample after healing can bear a weight of $500 \mathrm{~g}$ as shown in Fig. 10; furthermore, the figure shows the tensile strength results before and after healing.

Self-healing electronic polymers are superior to ordinary electronic polymers, demonstrating this fact, Bhattacharya et al. (2019) developed fluorescent self-healing carbon dot/ polymer gels. They linked primary amine residues of polyethyleneimine network with aldehyde units of carbon dot's top. This formed Schiff base linkage between these two precursors and endowed thus formed gel with self-healing abilities. Self-healing capabilities were judged by performing the rheological test, which show the remarkable self-healing
Fig. 10 a Self-healed vitrimer prepared from vanillin/xxylylenediamine and bisphenol A-based diglycidyl ether lifting a weight of $500 \mathrm{~g}$ after healing to assess the strength of sample through the butterfly clip, the sample maintained it for 30 min without getting any second fracture, b Enlarge picture of sample showing self-healed place and $\mathbf{c}$ Tensile strength, elongation at break and young modulus properties of the original and healed sample along with self-healing efficiency, the black line is picturing strength of original while the red line is showing healed/ weld sample's stress before the break. Reprinted from (Liu et al. 2020b) with permission from Elsevier. Copyright (C) 2020 Elsevier (a)

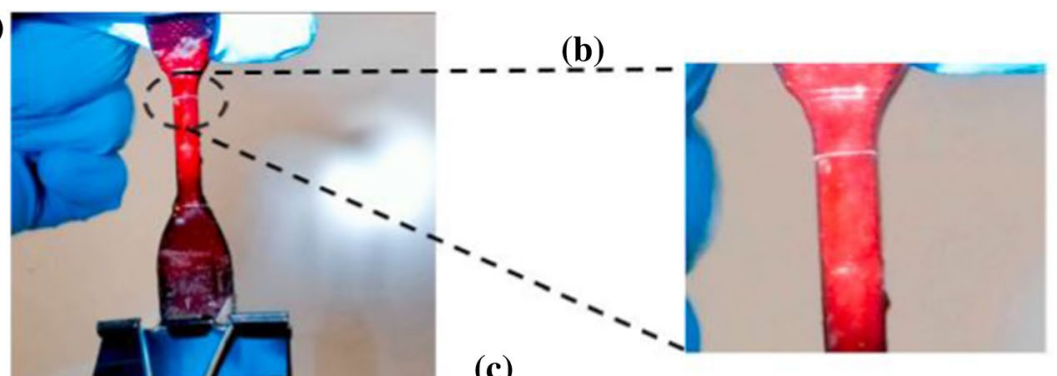

(c)

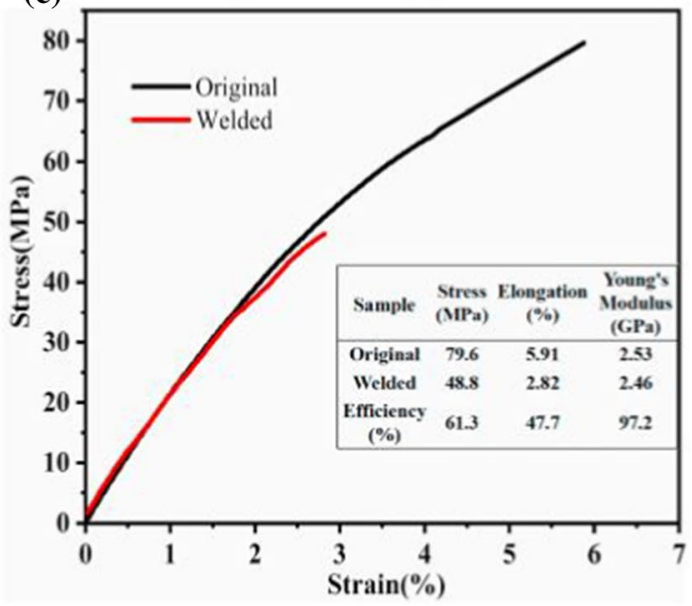


ability of the gel up to $100 \%$ recovery (Table 5). Gas-separation properties combining with self-healing ability can endow the separation films more reliability and durability, applying this concept, Ren et al. (2019) developed $\mathrm{CO}_{2} / \mathrm{N}_{2}$ separating films from chitosan and dialdehyde starch. Crosslinking dialdehyde starch with chitosan formed double crosslinked films with self-healing abilities. Optical microscopy was used to assess the self-healing abilities, i.e. the film was cut into pieces and placed together in a humid environment; the mobility provided the film's ease of reconstruction. The best-optimized sample yield $88.4 \%$ self-healing efficiency.

Ren et al. (2018) fabricated films based on metal chelation and Schiff-base utilizing ethylene glycol with dialdehyde modified group and chitosan. The imine linkage was formed between aldehyde groups of ethylene glycol with dialdehyde modified group and amino groups of chitosan endowing the films self-healing capabilities combined with metal chelation. Healing properties were demonstrated using optical microscopy such as cuts were made on the surface of films that disappeared in 30 min showing remarkable selfhealing properties of these films. To reconfirm the healing properties, force-displacement curves tests were performed.
After the one-damage recovered process, the self-healing reached 98\% (Table 5) for the best sample proving excellent self-healing. While after five damage/healing processes, the self-healing for the best sample reached $80 \%$.

\section{Conclusion}

Over the years, the research community has developed and capitalized on advanced materials with multifunction. Materials with various properties make them superior to classic counterparts that eventually ease the common life. Self-healing materials are the consequence of the struggles to fabricate superior materials. Self-healing is a phenomenon of self-repairing of materials once disrupted or destroyed based on different chemistries. There are two basic mechanisms of self-healing called intrinsic and extrinsic self-healing. Intrinsic self-healing materials are independent of external stimuli, while extrinsic self-healing requires some external stimulus to initiate the process. Dynamic chemistry-based bonds such as reversible chemical covalent bonds and physical non-covalent interactions have gain greater attention

Table 5 Details of self-healing 3D printings, electronics and films-based materials on Schiff base linkage

\begin{tabular}{|c|c|c|c|c|c|c|}
\hline Materials & $\begin{array}{l}\text { Tests performed for } \\
\text { self-healing }\end{array}$ & Healing efficiency & $\begin{array}{l}\text { External stimulus } \\
\text { condition }\end{array}$ & $\begin{array}{l}\text { Format } \\
\text { of dam- } \\
\text { age }\end{array}$ & Applications & References \\
\hline $\begin{array}{l}\text { Collagen, and oxi- } \\
\text { dized alginate }\end{array}$ & $\begin{array}{l}\text { Visual inspection } \\
\text { and optical micros- } \\
\text { copy }\end{array}$ & - & No external stimulus & Cut & $\begin{array}{l}\text { Meniscal tissue } \\
\text { development, 3D } \\
\text { printing }\end{array}$ & Gupta et al. (2020) \\
\hline $\begin{array}{l}\text { Glycol chitosan and } \\
\text { oxidized hyaluro- } \\
\text { nate }\end{array}$ & $\begin{array}{l}\text { Visual and opti- } \\
\text { cal microscopy, } \\
\text { Amplitude sweep } \\
\text { test }\end{array}$ & $\sim 100 \%$ & No external stimulus & Cut & $\begin{array}{l}\text { Tissue engineering } \\
\text { scaffolds, drug } \\
\text { delivery system }\end{array}$ & Ko et al. (2020) \\
\hline $\begin{array}{l}\mathrm{NH}_{2} \text { - polydimethyl- } \\
\text { siloxane-NH2 } \\
\left(\mathrm{NH}_{2}-\mathrm{PDMS}-\mathrm{NH} 2\right) \\
\text { and tris(4-formyl- } \\
\text { phenoxy) methyl- } \\
\text { ethane (TFME) }\end{array}$ & Tensile tests, & $\sim 100 \%$ & No external stimulus & Cut & $\begin{array}{r}\text { Flexible electronics, } \\
\text { electret generators }\end{array}$ & Yang et al. (2020b) \\
\hline $\begin{array}{l}\text { Qatarized chitosan } \\
\text { and oxidized } \\
\text { dextran }\end{array}$ & Rheological tests & - & No external stimulus & Cut & $\begin{array}{l}\text { Sensor, glucose } \\
\text { monitoring }\end{array}$ & Liang et al. (2019b) \\
\hline $\begin{array}{l}\text { Bisphenol A diglyci- } \\
\text { dyl ether (DGEBA), } \\
\text { m-xylylenediamine, } \\
\text { vanillin }\end{array}$ & $\begin{array}{l}\text { Optical microscopy, } \\
\text { Visual inspection }\end{array}$ & $\sim 97.2 \%$ & $120{ }^{\circ} \mathrm{C}$ & Crack & $\begin{array}{l}\text { Sustainable struc- } \\
\text { tural material }\end{array}$ & Liu et al. (2020b) \\
\hline $\begin{array}{l}\text { Polyethyleneimine } \\
\text { network and carbon } \\
\text { dots }\end{array}$ & Rheological tests & $\sim 100 \%$ & No external stimulus & Cut & Light emitters & $\begin{array}{l}\text { Bhattacharya et al. } \\
\text { (2019) }\end{array}$ \\
\hline $\begin{array}{l}\text { Dialdehyde starch and } \\
\text { chitosan }\end{array}$ & $\begin{array}{l}\text { Stress-displacement } \\
\text { tests }\end{array}$ & $\sim 88.4 \%$ & Humid environment & Crack & Gas separation films & Ren et al. (2019) \\
\hline $\begin{array}{l}\text { Ethylene glycol with } \\
\text { dialdehyde modified } \\
\text { group and chitosan }\end{array}$ & $\begin{array}{l}\text { Force-displacement } \\
\text { curves tests }\end{array}$ & $\sim 98 \%$ & No external stimulus & Crack & $\begin{array}{l}\text { Anticancer coatings, } \\
\text { medicine }\end{array}$ & Ren et al. (2018) \\
\hline
\end{tabular}


because of their suitability and strong nature comparatively. Schiff base bond has been widely used in self-healing materials because of the facile fabrication and non-stimulated recoupling after uncoupling, at ambient conditions. This work has summarized recent development and future prospects of self-healing polymers based on Schiff base bond. Most of the polymers, based on this bond, after healing were as strong as a virgin showing almost $100 \%$ recovery. Moreover, the fabrication process of different polymers was at mild conditions and maximum polymer healed without any external stimulus that proves the superiority of Schiff base bonds. However, it was felt that standardized testing methods for mechanical characterization and morphological/topological observations need to be developed. Talking about morphological characterization, characterizations from the atomic scale to macroscopic scale are necessary as they might give more detail about self-healing mechanism. Additionally, this qualitative and visual information needs to be translated into some numerical/quantitative datum. Summarising self-healing polymers in recent times have substantially progressed. Polymers with self-healing properties have become the prime focus; the number of researches on self-healing polymers is increasing day by day. The focus is on facile fabrication and quick self-integration, which has been answered through simple self-healing mechanisms such as Schiff-base bond-based materials.

Acknowledgements The authors are grateful for the financial supports from the Engineering and Physical Sciences Research Council (EPSRC) UK and from the Higher Education Commission of Pakistan to carry on this research.

Authors Contributions U. S. M; Conceptualization, Methodology, Software. M. B. K. N., Z. J.; Data curation, Writing- Original draft preparation. M. I. Z., F. S., M. B. K. N, Dai-Viet N. Vo: Visualization, Investigation. F. S.: Supervision.; S. A. U. H., D.-V. N. V.; Software, Validation.: D.-V. N. V., F. S.: Writing- Reviewing, Editing and Funding.

\section{Declarations}

Conflict of interest The authors declare that they have no known competing financial interests or personal relationships that could have appeared to influence the work reported in this paper.

Open Access This article is licensed under a Creative Commons Attribution 4.0 International License, which permits use, sharing, adaptation, distribution and reproduction in any medium or format, as long as you give appropriate credit to the original author(s) and the source, provide a link to the Creative Commons licence, and indicate if changes were made. The images or other third party material in this article are included in the article's Creative Commons licence, unless indicated otherwise in a credit line to the material. If material is not included in the article's Creative Commons licence and your intended use is not permitted by statutory regulation or exceeds the permitted use, you will need to obtain permission directly from the copyright holder. To view a copy of this licence, visit http://creativecommons.org/licenses/by/4.0/.

\section{References}

Acosta S, Ibañez-Fonseca A, Aparicio C, Rodríguez-Cabello JC (2020) Antibiofilm coatings based on protein-engineered polymers and antimicrobial peptides for preventing implant-associated infections. Biomater Sci 8(10):2866-2877. https://doi.org/10.1039/ D0BM00155D

Ahmadi M, Ghanavati M (2020) Dynamics of self-healing supramolecular guanine-modified poly (n-butyl methacrylate-co-hydroxyethyl methacrylate) copolymers. Polymer 211:123117. https:// doi.org/10.1016/j.polymer.2020.123117

AlMaadeed MAA, Ponnamma D, El-Samak AA (2020) Polymers to improve the world and lifestyle: physical, mechanical, and chemical needs. In 'Polymer Science and Innovative Applications'. (Eds MAA AlMaadeed, D Ponnamma, MA Carignano) pp 1-19 (Elsevier)

Atta AM, Ahmed AM, Al-Lohedan AH, El-Faham AJC (2020) Multifunctional cardanol triazine schiff base polyimine additives for self-healing and super-hydrophobic epoxy of steel coating. Coatings 10(4):327. https://doi.org/10.3390/coatings10040327

Balaji K, Singh M, Pathasarthy V, Park C, Sahoo NG, Yun GJ, Rana S (2020) Disulfide exchange assisted self-healing Epoxy/PDMS/ Graphene oxide nanocomposites. Nanoscale Adv. https://doi.org/ 10.1039/D0NA00282H

Balitaan JNI, Hsiao C-D, Yeh J-M, Santiago KSJIJOBM (2020) Innovation inspired by nature: biocompatible self-healing injectable hydrogels based on modified- $\beta$-chitin for wound healing. Int $\mathbf{J}$ Biol Macromol 162:723-736. https://doi.org/10.1016/j.ijbiomac. 2020.06.129

Basu S, Pacelli S, Paul AJAB (2020) Self-healing DNA-based injectable hydrogels with reversible covalent linkages for controlled drug delivery. Acta Biomater 105:159-169. https://doi.org/10. 1016/j.actbio.2020.01.021

Batista RA, Espitia PJP, Quintans JdSS, Freitas MM, Cerqueira MÂ, Teixeira JA, Cardoso JC (2019) Hydrogel as an alternative structure for food packaging systems. Carbohyd Polym 205:106-116. https://doi.org/10.1016/j.carbpol.2018.10.006

Bertran O, Saldías C, Díaz DD, Alemán C (2020) Molecular dynamics simulations on self-healing behavior of ionene polymer-based nanostructured hydrogels. Polymer 211:1230-1272. https://doi. org/10.1016/j.polymer.2020.123072

Bhattacharya S, Phatake RS, NabhaBarnea S, Zerby N, Zhu J-J, Shikler R, Lemcoff NG, Jelinek RJAN (2019) Fluorescent self-healing carbon dot/polymer gels. ACS Nano 13(2):1433-1442. https:// doi.org/10.1021/acsnano.8b07087

Bui R, Brook MAJP (2019) Dynamic covalent Schiff-base silicone polymers and elastomers. Polymer 160:282-290. https://doi.org/ 10.1016/j.polymer.2018.11.043

Chai Q, Jiao Y, Yu X (2017) Hydrogels for biomedical applications: their characteristics and the mechanisms behind them. Gels 3(1):1-15. https://doi.org/10.3390/gels3010006

Chaudhary V, Ahmad F (2020) A review on plant fiber reinforced thermoset polymers for structural and frictional composites. Polym Test. https://doi.org/10.1016/j.polymertesting.2020.106792

Chen Y, Guan ZJCC (2014) Multivalent hydrogen bonding block copolymers self-assemble into strong and tough self-healing materials. Chem Commun 50(74):10868-10870. https://doi.org/ 10.1039/C4CC03168G

Chen H, Cheng J, Ran L, Yu K, Lu B, Lan G, Dai F, Lu FJIOC (2018) An injectable self-healing hydrogel with adhesive and antibacterial properties effectively promotes wound healing. Prog Organ Coat 201:522-531. https://doi.org/10.1016/j.carbpol.2018.08. 090

Chen X, Fan M, Tan H, Ren B, Yuan G, Jia Y, Li J, Xiong D, Xing X, Niu XJMS (2019) Magnetic and self-healing chitosan-alginate 
hydrogel encapsulated gelatin microspheres via covalent crosslinking for drug delivery. Mater Sci Eng, C 101:619-629. https:// doi.org/10.1016/j.msec.2019.04.012

Cheng K-C, Huang C-F, Wei Y, S-hJNAM H (2019) Novel chitosan-cellulose nanofiber self-healing hydrogels to correlate self-healing properties of hydrogels with neural regeneration effects. NPG Asia Mater 11(1):1-17. https://doi.org/10.1038/ s41427-019-0124-z

Cummings SC, Dodo OJ, Hull AC, Zhang B, Myers CP, Sparks JL, Konkolewicz D (2020) Quantity or quality: are self-healing polymers and elastomers always tougher with more hydrogen bonds? ACS Appl Polym Mater 2(3):1108-1113. https://doi.org/ 10.1021/acsapm.9b01095

Da Silva CM, da Silva DL, Modolo LV, Alves RB, de Resende MA, Martins CV, de Fátima Â (2011) Schiff bases: a short review of their antimicrobial activities. J Adv Res 2(1):1-8. https://doi.org/ 10.1016/j.jare.2010.05.004

Dai X, Du Y, Yang J, Wang D, Gu J, Li Y, Wang S, Xu BB, Kong J (2019) Recoverable and self-healing electromagnetic wave absorbing nanocomposites. Compos Sci Technol 174:27-32. https://doi.org/10.1016/j.compscitech.2019.02.018

Deng Z, Wang H, Ma PX, Guo B (2020) Self-healing conductive hydrogels: preparation, properties and applications. Nanoscale 12(3):1224-1246. https://doi.org/10.1039/C9NR09283H

Ding F, Zou Y, Wu S, Zou X (2020) Self-healing and tough hydrogels with conductive properties prepared through an interpenetrating polymer network strategy. Polymer 206:122907. https://doi.org/ 10.1016/j.polymer.2020.122907

Ehrhardt D, Mangialetto J, Bertouille J, Van Durme K, Van Mele B, Van den Brande NJP (2020) Self-healing in mobility-restricted conditions maintaining mechanical robustness: furan-maleimide diels-alder cycloadditions in polymer networks for ambient applications. Polymers 12(11):2543. https://doi.org/10.3390/ polym 12112543

Fan T, Chen G, Xie H, Su B, hui He MJCEJ, (2020) Highly Transparent, Self-Healing Conductive Elastomers Enabled by Synergistic Hydrogen Bonding Interactions. Chem Eng J 393:1-8. https:// doi.org/10.1016/j.cej.2020.124685

Gao S, Cheng Z, Zhou X, Liu Y, Wang J, Wang C, Chu F, Xu F, Zhang DJCEJ (2020) Fabrication of lignin based renewable dynamic networks and its applications as self-healing, antifungal and conductive adhesives. Chem Eng J. https://doi.org/10.1016/j. cej.2020.124896

Ghaffar SH, Fan MJIJOA (2014) Lignin in straw and its applications as an adhesive. Int J Adhesion Adhesives 48:92-101. https://doi. org/10.1016/j.ijadhadh.2013.09.001

Gong X, Cheng Z, Gao S, Zhang D, Ma Y, Wang J, Wang C, Chu FJCP (2020) Ethyl cellulose based self-healing adhesives synthesized via RAFT and aromatic schiff-base chemistry. Carbohyd Polym 250:116846. https://doi.org/10.1016/j.carbpol.2020.116846

Grande AM, Bijleveld J, Garcia S, van Der Zwaag SJP (2016) A combined fracture mechanical-rheological study to separate the contributions of hydrogen bonds and disulphide linkages to the healing of poly (urea-urethane) networks. Polymer 96:26-34. https://doi.org/10.1016/j.polymer.2016.05.004

Guo B, Qu J, Zhao X, Zhang MJAB (2019) Degradable conductive self-healing hydrogels based on dextran-graft-tetraaniline and $\mathrm{N}$-carboxyethyl chitosan as injectable carriers for myoblast cell therapy and muscle regeneration. Acta Biomaterialia 84:180 193. https://doi.org/10.1016/j.actbio.2018.12.008

Gupta S, Sharma A, Kumar JV, Sharma V, Gupta PK, Verma RSJIJOBM (2020) Meniscal tissue engineering via 3D printed PLA monolith with carbohydrate based self-healing interpenetrating network hydrogel. Int J Biol Macromol 162:1358-1371. https:// doi.org/10.1016/j.ijbiomac.2020.07.238
Han X, Meng X, Wu Z, Wu Z, Qi XJMS (2018) Dynamic imine bond cross-linked self-healing thermosensitive hydrogels for sustained anticancer therapy via intratumoral injection. Mater Sci Eng, C 93:1064-1072. https://doi.org/10.1016/j.msec.2018.08.064

He J, Shi M, Liang Y, Guo BJCEJ (2020) Conductive adhesive selfhealing nanocomposite hydrogel wound dressing for photothermal therapy of infected full-thickness skin wounds. Chem Eng J 394:124888. https://doi.org/10.1016/j.cej.2020.124888

Jia Z, Zhu S, Chen Y, Zhang W, Zhong B, Jia DJCPAAS (2020) Recyclable and self-healing rubber composites based on thermorevesible dynamic covalent bonding. Compos Part a Appl Sci Manuf 129:105-112. https://doi.org/10.1016/j.compositesa.2019. 105709

Jiang D, Wang Y, Li B, Sun C, Wu Z, Yan H, Xing L, Qi S, Li Y, Liu HJMM (2019) Flexible sandwich structural strain sensor based on silver nanowires decorated with self-healing substrate. Macromol Mater Eng 304(7):1-9. https://doi.org/10.1002/mame. 201900074

Jud K, Kausch H, Williams J (1981) Fracture mechanics studies of crack healing and welding of polymers. J Mater Sci 16(1):204210. https://doi.org/10.1007/BF00552073

Kalia S (2016) Polymeric hydrogels as smart biomaterials. Springer, Cham

Kian L, Saba N, Jawaid M, Sultan M (2019) A review on processing techniques of bast fibers nanocellulose and its polylactic acid (PLA) nanocomposites. Int J Biol Macromol 121:1314-1328. https://doi.org/10.1016/j.ijbiomac.2018.09.040

Ko ES, Kim C, Choi Y, Lee KYJCP (2020) 3D printing of self-healing ferrogel prepared from glycol chitosan, oxidized hyaluronate, and iron oxide nanoparticles. Carbohyd Polym. https://doi.org/10. 1016/j.carbpol.2020.116496

KumiBarimah E, Rahayu S, Ziarko MW, Bamiedakis N, White IH, Penty RV, Kale GM, Jose G (2020) Erbium-doped nanoparticlepolymer composite thin films for photonic applications: structural and optical properties. ACS Omega 5(16):9224-9232. https://doi.org/10.1021/acsomega.0c00040

Lai S-M, Liu J-L, Huang Y-HJJOMS, Part B (2020) Preparation of self-healing natural rubber/polycaprolactone (NR/PCL) blends. J Macromol Sci Part B. https://doi.org/10.1080/00222348.2020. 1757218

Lee S-H, Shin S-R, Lee D-SJM (2019) Self-healing of cross-linked PU via dual-dynamic covalent bonds of a Schiff base from cystine and vanillin. Mater Des 172:107774. https://doi.org/10.1016/j. matdes.2019.107774

Lei ZQ, Xie P, Rong MZ, Zhang MQ (2015) Catalyst-free dynamic exchange of aromatic Schiff base bonds and its application to self-healing and remolding of crosslinked polymers. J Mater Chem A 3(39):19662-19668. https://doi.org/10.1039/C5TA0 $5788 \mathrm{D}$

Li G, Xiao P, Hou S, Huang YJC (2019) Graphene based self-healing materials. Carbon 146:371-387. https://doi.org/10.1016/j.carbon. 2019.02.011

Li S, Pei M, Wan T, Yang H, Gu S, Tao Y, Liu X, Zhou Y, Xu W, Xiao P (2020a) Self-healing hyaluronic acid hydrogels based on dynamic Schiff base linkages as biomaterials. Carbohyd Polym 250:116922. https://doi.org/10.1016/j.carbpol.2020.116922

Li Z, de Souza LR, Litina C, Markaki AE, Al-Tabbaa A (2020b) A novel biomimetic design of a 3D vascular structure for self-healing in cementitious materials using Murray's law. Mater Des 190:1-14. https://doi.org/10.1016/j.matdes.2020.108572

Liang K, Bae KH, Kurisawa M (2019a) Recent advances in the design of injectable hydrogels for stem cell-based therapy. J Mater Chem B 7(24):3775-3791. https://doi.org/10.1039/C9TB00485H

Liang T, Zou L, Guo X, Ma X, Zhang C, Zou Z, Zhang Y, Hu F, Lu Z, Tang KJAFM (2019b) Rising mesopores to realize direct electrochemistry of glucose oxidase toward highly sensitive detection 
of glucose. Adv Func Mater 29(44):1903026. https://doi.org/10. 1002/adfm.201903026

Lin TW, Hsu Sh (2020) Self-healing hydrogels and cryogels from biodegradable polyurethane nanoparticle crosslinked chitosan. Adv Sci 7(3):1901388. https://doi.org/10.1002/advs.201901388

Liu Y, Hsu S-HJFIC (2018) Synthesis and biomedical applications of self-healing hydrogels. Front Chem 6:449-457. https://doi. org/10.3389/fchem.2018.00449

Liu Q, Ji N, Xiong L, Sun Q (2020a) Rapid gelling, self-healing, and fluorescence-responsive chitosan hydrogels formed by dynamic covalent crosslinking. Carbohyd Polym. https://doi. org/10.1016/j.carbpol.2020.116586

Liu X, Liang L, Lu M, Song X, Liu H, Chen GJP (2020b) Waterresistant bio-based vitrimers based on dynamic imine bonds: self-healability, remodelability and ecofriendly recyclability. Polymer 210:123030. https://doi.org/10.1016/j.polymer.2020. 123030

Luan Y-G, Zhang X-A, Jiang S-L, Chen J-H, Lyu Y-F (2018) Selfhealing supramolecular polymer composites by hydrogen bonding interactions between hyperbranched polymer and graphene oxide. Chin J Polym Sci 36(5):584-591. https://doi.org/10.1007/ s10118-018-2025-y

Luo C, Li M, Yuan R, Yang Y, Lu Z, Ge LJAABM (2020) Biocompatible self-healing coating based on schiff base for promoting adhesion of coral cells. ACS Appl Bio Mater 3(3):1481-1495. https://doi.org/10.1021/acsabm.9b01113

Mohamadhoseini M, Mohamadnia ZJCCR (2020) Supramolecular selfhealing materials via host-guest strategy between cyclodextrin and specific types of guest molecules. Coord Chem Rev. https:// doi.org/10.1016/j.ccr.2020.213711

NajwaThajudin NL, Zainol MH, Shuib RK (2021) Intrinsic room temperature self-healing natural rubber based on metal thiolate ionic network. Polym Test 93:106975. https://doi.org/10.1016/j.polym ertesting.2020.106975

Nie J, Huang J, Fan J, Cao L, Xu C, Chen Y (2020) Strengthened, self-healing, and conductive ENR-based composites based on multiple hydrogen bonding interactions. ACS Sustain Chem Eng 8(36):13724-13733. https://doi.org/10.1021/acssuschem eng.0c04136

Nor AFM, Sultan MTH, Jawaid M, Azmi AMR, Shah AUM (2019) Analysing impact properties of CNT filled bamboo/glass hybrid nanocomposites through drop-weight impact testing, UWPI and compression-after-impact behaviour. Compos B Eng 168:166174. https://doi.org/10.1016/j.compositesb.2018.12.061

Pc JE, Sultan MT, Selvan CP, Irulappasamy S, Mustapha F, Basri AA, Safri SN (2020) Manufacturing challenges in self-healing technology for polymer composites-a review. J Market Res 9(4):7370-7379. https://doi.org/10.1016/j.jmrt.2020.04.082

Qian C, Zhang T, Gravesande J, Baysah C, Song X, Xing JJIJOBM (2019) Injectable and self-healing polysaccharide-based hydrogel for $\mathrm{pH}$-responsive drug release. Int J Biol Macromol 123:140148. https://doi.org/10.1016/j.ijbiomac.2018.11.048

Qu J, Zhao X, Liang Y, Zhang T, Ma PX, Guo B (2018) Antibacterial adhesive injectable hydrogels with rapid self-healing, extensibility and compressibility as wound dressing for joints skin wound healing. Int J Biol Macromol 183:185-199. https://doi.org/10. 1016/j.biomaterials.2018.08.044

Rahmani S, Barzegar M (2020) One-pot synthesis of dibenzaldehydeterminated poly (ethylene glycol) for preparation of dynamic chitosan-based amphiphilic hydrogels. Polym Bull. https://doi. org/10.1007/s00289-020-03244-x

Reddy KR, El-Zein A, Airey DW, Alonso-Marroquin F, Schubel P, Manalo A (2020) Self-healing polymers: synthesis methods and applications. Nano-Struct Nano-Objects 23:100500. https://doi. org/10.1016/j.nanoso.2020.100500
Ren J, Xuan H, Dai W, Zhu Y, Ge L (2018) Double network selfhealing film based on metal chelation and Schiff-base interaction and its biological activities. Appl Surf Sci 448:609-617. https:// doi.org/10.1016/j.apsusc.2018.04.122

Ren J, Xuan H, Ge L (2019) Double network self-healing chitosan/ dialdehyde starch-polyvinyl alcohol film for gas separation. Appl Surf Sci 469:213-219. https://doi.org/10.1016/j.apsusc.2018.11. 001

Ren J, Li M, Yuan R, Pang A, Lu Z, Ge LJC (2020) Adherent selfhealing chitosan/dialdehyde starch coating. Physicochem Eng Aspects 586:124203. https://doi.org/10.1016/j.colsurfa.2019. 124203

Romero M, Macchione MA, Mattea F, Strumia M (2020) The role of polymers in analytical medical applications. Rev Microchem J. https://doi.org/10.1016/j.microc.2020.105366

Sadasivuni KK, Hegazy SM, Aly AAMA, Waseem S, Karthik K (2020) Chapter 11 - Polymers in electronics. In: AlMaadeed MAA, Ponnamma D, Carignano MA (eds) Polymer science and innovative applications. Elsevier, pp 365-392. https://doi.org/10.1016/ B978-0-12-816808-0.00011-1

Schiff H (1864) Mittheilungen aus dem Universitätslaboratorium in Pisa: eine neue Reihe organischer Basen. Justus Liebigs Ann Chem 131(1):118-119. https://doi.org/10.1002/jlac.18641 310113

Sharma S, Jain P, Tiwari S (2020) Dynamic imine bond based chitosan smart hydrogel with magnified mechanical strength for controlled drug delivery. Int J Biol Macromol. https://doi.org/10.1016/j.ijbio mac.2020.05.221

Sinawang G, Osaki M, Takashima Y, Yamaguchi H, Harada A (2020) Supramolecular self-healing materials from non-covalent crosslinking host-guest interactions. Chem Commun 56(32):43814395. https://doi.org/10.1039/D0CC00672F

Slaughter BV, Khurshid SS, Fisher OZ, Khademhosseini A, Peppas NA (2009) Hydrogels in regenerative medicine. Adv Mater 21(32-33):3307-3329. https://doi.org/10.1002/adma.200802106

Spicer CD (2020) Hydrogel scaffolds for tissue engineering: the importance of polymer choice. Polym Chem 11(2):184-219. https:// doi.org/10.1039/C9PY01021A

Sultan M, Worden K, Staszewski W, Pierce S, Dulieu-Barton J, Hodzic A (2009) Impact damage detection and quantification in CFRP laminates; a precursor to machine learning

Sun M, Qiu J, Jin S, Liu W, Sakai E (2020a) Visible light induced synthesis of high toughness, self-healing ionic hydrogel and its application in strain sensing. Colloids Surf, A 607:489-495. https://doi.org/10.1016/j.colsurfa.2020.125438

Sun Y, Liu W, Xu D, Li X, Li C (2020b) Self-healing of super hydrophobic and hierarchical surfaces for gas diffusion layer. Int J Hydrogen Energy 45(54):29774-29781. https://doi.org/10. 1016/j.ijhydene.2019.09.065

Surendran A, Thomas S (2020) Self-healing polymeric systems-fundamentals, state of art, and challenges. In 'Self-Healing Polymerbased Systems'. pp 1-16 (Elsevier) https://doi.org/10.1016/B9780-12-818450-9.00001-5

Talebian S, Mehrali M, Taebnia N, Pennisi CP, Kadumudi FB, Foroughi J, Hasany M, Nikkhah M, Akbari M, Orive G (2019) Selfhealing hydrogels: the next paradigm shift in tissue engineering? Adv Sci 6(16): 1801664

Tamate R, Hashimoto K, Horii T, Hirasawa M, Li X, Shibayama M, Watanabe M (2018) Self-healing micellar ion gels based on multiple hydrogen bonding. Adv Mater 30(36):1802792. https://doi. org/10.1002/adma.201802792

Tang J, Wan L, Zhou Y, Pan H, Huang FJJOMCA (2017) Strong and efficient self-healing adhesives based on dynamic quaternization cross-links. J Mater Chem A 5(40):21169-21177. https://doi.org/ 10.1039/C7TA06650C 
Tian X, Yang P, Yi Y, Liu P, Wang T, Shu C, Qu L, Tang W, Zhang Y, Li M (2020) Self-healing and high stretchable polymer electrolytes based on ionic bonds with high conductivity for lithium batteries. J Power Sour 450:227629. https://doi.org/10.1016/j. jpowsour.2019.227629

Tseng TC, Tao L, Hsieh FY, Wei Y, Chiu IM, Hsu Sh (2015) An injectable, self-healing hydrogel to repair the central nervous system. Adv Mater 27(23):3518-3524. https://doi.org/10.1002/adma. 201500762

Tu Y, Chen N, Li C, Liu H, Zhu R, Chen S, Xiao Q, Liu J, Ramakrishna S, He LJAB (2019) Advances in injectable self-healing biomedical hydrogels. Acta Biomater 90:1-20. https://doi.org/10.1016/j. actbio.2019.03.057

Utrera-Barrios S, Verdejo R, López-Manchado MA, Santana MHJMH (2020) Evolution of self-healing elastomers, from extrinsic to combined intrinsic mechanisms: a review. Mater Horiz 7(11):2882-2902. https://doi.org/10.1039/D0MH00535E

Vijayan P, AlMaadeed M (2016) "Containers" for self-healing epoxy composites and coating: trends and advances. Express Polym Lett 10(6):506-524. https://doi.org/10.3144/expresspolymlett. 2016.48

Wang C, Wang M, Xu T, Zhang X, Lin C, Gao W, Xu H, Lei B, Mao CJT (2019) Engineering bioactive self-healing antibacterial exosomes hydrogel for promoting chronic diabetic wound healing and complete skin regeneration. Theranostics 9(1):65

Wang J-K, Zhou Q, Wang J-P, Yang S, Li GLJC, Physicochemical SA, Aspects E (2019b) Hydrophobic self-healing polymer coatings from carboxylic acid-and fluorine-containing polymer nanocontainers. Physicochem Eng Aspects 569:52-58. https://doi.org/10. 1016/j.colsurfa.2019.02.050

Wang Y, Jiang D, Zhang L, Li B, Sun C, Yan H, Wu Z, Liu H, Zhang J, Fan J (2019c) Hydrogen bonding derived self-healing polymer composites reinforced with amidation carbon fibers. Nanotechnology 31(2):1-13. https://doi.org/10.1088/1361-6528/ab4743

Wang Z, Lu X, Sun S, Yu C, Xia HJJOMCB (2019d) Preparation, characterization and properties of intrinsic self-healing elastomers. J Mater Chem B 7(32):4876-4926. https://doi.org/10.1039/ C9TB00831D

Wang M, Chen M, Niu W, Winston DD, Cheng W, Lei BJB (2020a) Injectable biodegradation-visual self-healing citrate hydrogel with high tissue penetration for microenvironment-responsive degradation and local tumor therapy. Biomaterials 261:120301. https://doi.org/10.1016/j.biomaterials.2020.120301

Wang X, Liang D, Cheng B (2020b) Preparation and research of intrinsic self-healing elastomers based on hydrogen and ionic bond. Compos Sci Technol. https://doi.org/10.1016/j.compscitech. 2020.108127

Wang Z, Guo L, Xiao H, Cong H, Wang S (2020c) A reversible underwater glue based on photo-and thermo-responsive dynamic covalent bonds. Mater Horiz 7(1):282-288. https://doi.org/10.1039/ C9MH01148J

Weimer RB, Wright DM, Hodgins T (2020) Paints and polymers. Handbook Trace Evid Anal. https://doi.org/10.1002/9781119373 438.ch3

Wolfel A, Igarzabal CIA, Romero MR (2020) Imine bonding self-repair hydrogels after periodate-triggered breakage of their cross-links. Eur Polymer J 140:110038. https://doi.org/10.1016/j.eurpolymj. 2020.110038

Xiong Y, Zhu M, Wang Z, Schneider J, Huang H, Kershaw SV, Zhi C, Rogach AL (2018) A building brick principle to create transparent composite films with multicolor emission and self-healing function. Nano Micro Small 14(20):1800315. https://doi.org/10. 1002/smll.201800315

Xu C, Zhan W, Tang X, Mo F, Fu L, Lin BJPT (2018) Self-healing chitosan/vanillin hydrogels based on Schiff-base bond/hydrogen bond hybrid linkages. Polym Testing 66:155-163. https://doi.org/ 10.1016/j.polymertesting.2018.01.016

Xu J, Liu Y, Hsu S-HJM (2019) Hydrogels based on Schiff base linkages for biomedical applications. Molecules 24(16):3005. https:// doi.org/10.3390/molecules24163005

Yang M, Sun Y, Chen G, Wang G, Lin S, Sun ZJML (2020a) Preparation of a self-healing silicone coating for inhibiting adhesion of benthic diatoms. Mater Lett 268:127496. https://doi.org/10. 1016/j.matlet.2020.127496

Yang P-K, Zhu X-L, Huang L, Zhou Y, Song G-Q, Qin C-C, Wang D, Wu Y-PJCRPS (2020b) Skin-inspired electret nanogenerator with self-healing abilities. Cell Rep Phys Sci 1(9):100185. https://doi. org/10.1016/j.xcrp.2020.100185

Yang X, Guo L, Xu X, Shang S, Liu HJM (2020c) A fully bio-based epoxy vitrimer: self-healing, triple-shape memory and reprocessing triggered by dynamic covalent bond exchange. Mater Des 186:108248. https://doi.org/10.1016/j.matdes.2019.108248

Ye J, Fu S, Zhou S, Li M, Li K, Sun W, Zhai YJEPJ (2020) Advances in hydrogels based on dynamic covalent bonding and prospects for its biomedical application. Eur Polymer J. https://doi.org/10. 1016/j.eurpolymj.2020.110024

Yong WF, Zhang H (2020) Recent advances in polymer blend membranes for gas separation and pervaporation. Prog Mater Sci. https://doi.org/10.1016/j.pmatsci.2020.100713

Yuan D, Sb D, Ke K, Raquez J-M, Dubois P, Manas-Zloczower I (2019) Biomimetic water-responsive self-healing epoxy with tunable properties. ACS Appl Mater Interfaces 11(19):1785317862. https://doi.org/10.1021/acsami.9b04249

Zhan J, Wu Y, Wang H, Liu J, Ma Q, Xiao K, Li Z, Li J, Luo F, Tan HJIJOBM (2020) An injectable hydrogel with pH-sensitive and self-healing properties based on 4armPEGDA and N-carboxyethyl chitosan for local treatment of hepatocellular carcinoma. Int J Biol Macromol 163:1208-1222. https://doi.org/10.1016/j. ijbiomac.2020.07.008

Zhang ZP, Rong MZ, Zhang MQJPiPS (2018) Polymer engineering based on reversible covalent chemistry: a promising innovative pathway towards new materials and new functionalities. Prog Polym Sci 80:39-93. https://doi.org/10.1016/j.progpolymsci. 2018.03.002

Zhang B, He J, Shi M, Liang Y, Guo B (2020a) Injectable self-healing supramolecular hydrogels with conductivity and photo-thermal antibacterial activity to enhance complete skin regeneration. Chem Eng J 400:125994. https://doi.org/10.1016/j.cej.2020. 125994

Zhang K, Liu Y, Wang Z, Song C, Gao C, Wu YJEPJ (2020b) A type of self-healable, dissoluble and stretchable organosilicon elastomer for flexible electronic devices. Eur Polymer J 134:109857. https:// doi.org/10.1016/j.eurpolymj.2020.109857

Zhang Q, Wu M, Hu X, Lu W, Wang M, Li T, Zhao Y (2020c) A novel double-network, self-healing hydrogel based on hydrogen bonding and hydrophobic effect. Macromol Chem Phys 221(3):1900320. https://doi.org/10.1002/macp.201900320

Zhao M, Tang Z, Zhang X, Li Z, Xiao H, Zhang M, Liu K, Ni Y, Huang L, Chen L (2020) A self-healing, stretchable, and conductive poly (N-vinylpyrrolidone)/gallic acid composite hydrogel formed via hydrogen bonding for wearable electronic sensors. Compos Sci Technol 198:108294. https://doi.org/10.1016/j.compscitech. 2020.108294

Zhou Y, Peng S, Hu J, He J (2017) Polymeric insulation materials for HVDC cables: development, challenges and future perspective. Handbook Trace Evid Anal 24(3):1308-1318. https://doi.org/10. 1109/TDEI.2017.006205

Zhou X, Li Y, Chen S, Fu Y-n, Wang S, Li G, Tao L, Wei Y, Wang X, Liang JFJC, Biointerfaces SB (2018) Dynamic agent of an injectable and self-healing drug-loaded hydrogel for embolization 
therapy. Colloids Surf B 172:601-607. https://doi.org/10.1016/j. colsurfb.2018.09.016

Zhu M, Jin H, Shao T, Li Y, Liu J, Gan L, Long MJM (2020) Polysaccharide-based fast self-healing ion gel based on acylhydrazone and metal coordination bonds. Mater Des 192:108723. https:// doi.org/10.1016/j.matdes.2020.108723
Publisher's Note Springer Nature remains neutral with regard to jurisdictional claims in published maps and institutional affiliations. 